\title{
Emotion-based personality traits and associations with conflict tactics and relationship satisfaction in romantic relationships
}

Christine A. Rudnicki

West Virginia University

Follow this and additional works at: https://researchrepository.wvu.edu/etd

\section{Recommended Citation}

Rudnicki, Christine A., "Emotion-based personality traits and associations with conflict tactics and relationship satisfaction in romantic relationships" (2002). Graduate Theses, Dissertations, and Problem Reports. 790.

https://researchrepository.wvu.edu/etd/790

This Thesis is protected by copyright and/or related rights. It has been brought to you by the The Research Repository @ WVU with permission from the rights-holder(s). You are free to use this Thesis in any way that is permitted by the copyright and related rights legislation that applies to your use. For other uses you must obtain permission from the rights-holder(s) directly, unless additional rights are indicated by a Creative Commons license in the record and/ or on the work itself. This Thesis has been accepted for inclusion in WVU Graduate Theses, Dissertations, and Problem Reports collection by an authorized administrator of The Research Repository @ WVU. For more information, please contact researchrepository@mail.wvu.edu. 
Emotion-Based Personality Traits and Associations with Conflict Tactics and Relationship Satisfaction in Romantic Relationships

\author{
Christine A. Rudnicki
}

Thesis submitted to the College of Arts and Sciences at West Virginia University

In partial fulfillment of the requirements

for the degree of

Master of Arts

in

Communication

Melanie Booth-Butterfield, Ph.D., Chair

Matthew M. Martin, Ph.D.

Keith Weber, Ph.D.

Department of Communication Studies

Morgantown, West Virginia

2002

Keywords: Romantic Relationships, Conflict Tactics, Affective Orientation, Emotional Intelligence, Relationship Satisfaction, Gender Comparisons. 


\author{
Abstract \\ Emotion-Based Personality Traits and Associations with Conflict Tactics and \\ Relationship Satisfaction in Romantic Relationships \\ By: Christine A. Rudnicki
}

The purpose of this study was to assess the role that emotion based personality traits play in conflict tactic choice and relationship satisfaction in romantic relationships. The researchers proposed that emotional intelligence and affective orientation influenced the choice of verbally aggressive or reasoning tactics use and their subsequent affects on overall relationship satisfaction. 159 participants, 84 men and 75 women, from a large Mid-Atlantic university participated in this study. Results showed that emotional intelligence and affective orientation were significantly correlated $(\mathrm{r}=.58)$, and that affective orientation in combination of the participants' perceptions of their partner's use of verbally aggressive, and reasoning tactics had the most influence on relationship satisfaction. There were gender differences in affective orientation and emotional intelligence, with females scoring higher, but not in the choice of conflict tactics. 


\section{DEDICATION}

The author wishes to thank her committee members, Melanie, Grand Pumbaa, and the Captain, for all of their support. Sorry about the hot tub Keith.

Thanks to Renee, the port in the storm of graduate school.

Thanks also to my fellow masters students. You have made the year interesting and challenging.

Thanks to my girls, you know who you are, for being there all the times I needed you, and keeping me together when I thought I would loose it.

Thanks to my mentor, Melissa Wanzer, and all my professors at Canisius who prepared me so well for this challenge.

Thanks to my family, my mom, dad, and sisters, who put up with me this year, who sent me notes and packages every week, I love you.

Thanks to my best friend Alice, who listened to all the stories, and brought me back to Reality, you are my favorite.

Thanks to Luke, for making me realize that four hours away from home, is nothing like living a hemisphere away from your home. Thanks for pushing me. 


\section{TABLE OF CONTENTS}

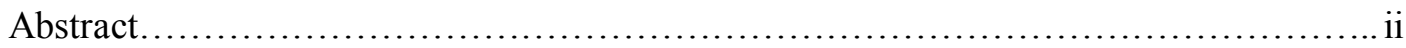

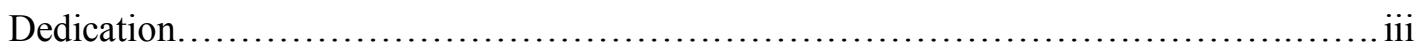

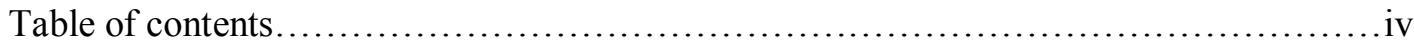

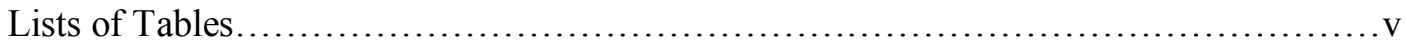

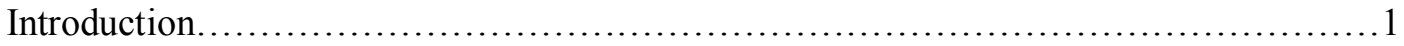

Chapter 1: Emotion and Communication.......................................... 2

Chapter 2: Emotional Intelligence............................................. 4

Chapter 3: Affective Orientation................................................ 8

Chapter 4: Conflict............................................................ 15

1. Section 1: Processing of Conflict.............................. 18

Chapter 5: Relationship Satisfaction........................................... 23

Chapter 6: Hypotheses and Research Question...................................... 26

Chapter 7: Method............................................................. 26

1. Section 1: Sample Population....................................... 26

2. Section 2: Procedures...............................................27

3. Section 3: Measures.............................................27

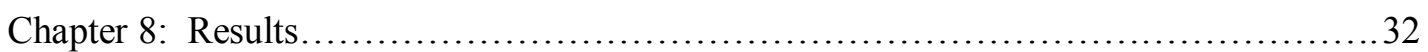

1. Section 1: Descriptive Statistics.................................... 32

2. Section 2: Tests of Hypotheses and Research Question................... 33

Chapter 9: Discussion...................................................... 37

Chapter 10: Limitations and Future Research..................................... 47

References......................................................................... 50

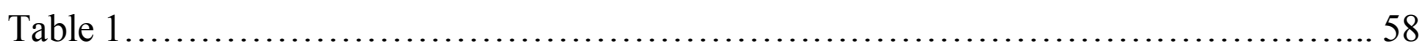

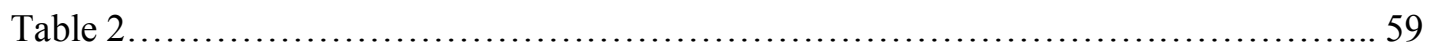

Appendix A............................................................... 60

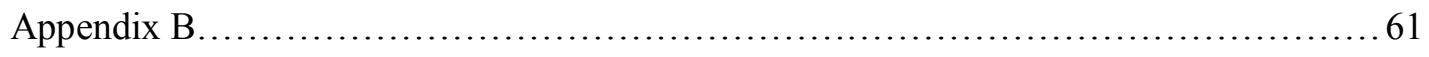

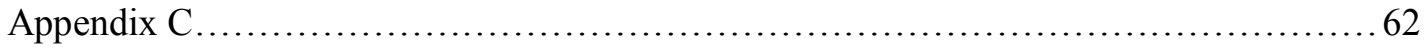

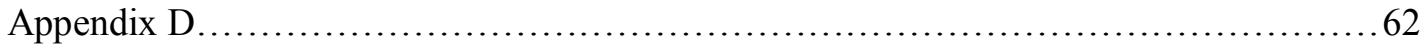

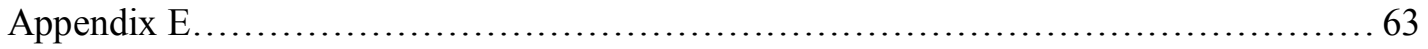

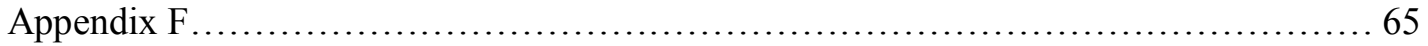

Appendix G............................................................... 66 


\section{LIST OF TABLES}

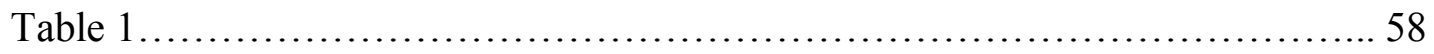

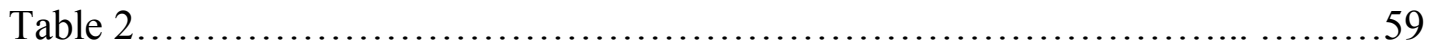


Emotion-Based Personality Traits and Associations with Conflict Tactics and Relationship Satisfaction in Romantic Relationships

Interpersonal scholars have studied conflict in both romantic and platonic relationships for decades (Anderson \& Guerrero, 1998). Recently, new constructs like emotional intelligence and affective orientation have emerged as formidable arenas for research in interpersonal relationships (Salovey \& Mayer, 1990; Booth-Butterfield \& Booth-Butterfield, 1990). These constructs have yet to be studied along side one another, and have not been associated with conflict in dyadic relationships, or together with relationship satisfaction. It is the position of the current argument that the degree to which people understand their emotions, the emotions of others, and use their emotions in decision making may play a role in the types of conflict tactics they utilize in romantic relationships. Though affective orientation has been examined along the lines of relationship satisfaction, it has not been studied along with conflict tactics and emotional intelligence (Booth-Butterfield, Hinkle, \& Booth-Butterfield, 1998). The following study examines emotional intelligence, affective orientation, conflict tactics, and relationship satisfaction.

The personality traits of affective orientation and emotional intelligence may also be key factors in determining the type of conflict tactics employed in interpersonal relationships and the subsequent relationship satisfaction in those interactions. The emotional intelligence construct measures how people recognize and understand their emotions (Salovey \& Mayer, 1990). The affective orientation construct assesses the degree to which people's perceived emotions influence their behavior (Booth-Butterfield \& Booth-Butterfield, 1990). Conflict tactics are choices and behaviors made in 
emotionally critical situations (Straus \& Gelles, 1990). Relationship satisfaction is an overall outcome variable that may result from a combination of the three aforementioned traits and behaviors. This research proposes a direct relationship between emotional intelligence, affective orientation, the use of reasoning conflict strategies, and relationship satisfaction in romantic relationships.

\section{CHAPTER 1: Emotion and Communication.}

Emotions are different than moods. It is imperative in emotion research that this differentiation is made. Emotions have an object, are brief in duration, and as compared to moods, are very intense. Moods are less intense and more enduring than emotions. Moods are not provoked by a particular incident or individual, but are more global and considered background states (Burleson \& Planalp, 2000). From these distinctions it can be asserted that emotion will be more influential than mood in communication. Differences between emotion and mood are difficult to measure since people may not be aware if what they are experiencing is a mood, or an emotion. Even if the participants can identify which, mood or emotion, they are having, there is another challenge for the researcher. The challenge lies in determining if emotion or mood is the sole influence of the outcome variable being studied. Emotion can also be expressed spontaneously and strategically (Knapp, 2000). This idea adds to the complexity involved in the study of emotion and its relation to communication.

Outside of the distinction between emotion and mood, emotion has many facets and effects linking it to communication. Emotions are elicited by communication, relayed through communication, and shared and socialized through communication (Anderson \& Guerrero, 1998). Emotions play major roles in making relationships, 
breaking them, motivation, decision-making, shaping public reactions, and bringing about altruism and values (Planalp, 1999). People make judgments about the values of their own emotions, the length of time that they experience them and with what intensity they are displayed (Knapp, 2000).

Emotion in communication can be studied and analyzed in a number of different ways. Researchers can look at how emotions are perceived and what influences them. The physical changes that may or may not accompany the emotion could be examined. Lastly, the actions and expressions accompanying the emotion, and the process involved in regulation of emotion can be examined (Knapp, 2000). Linking communication to emotion is the crux of this argument. The position of the current research is that emotion begins the conceptual linkage of emotion-based personality traits to conflict tactic choice and in turn affects overall relationship satisfaction. The communication during the conflict interaction, as influenced by emotion recognition and behavior based on that recognition, brings about satisfaction or lack of it in romantic relationships.

Research has shown that personality traits may influence how social situations are interpreted and thus how emotions are expressed. Social situations bring about arousal, which causes specific emotions, and empathy in individuals (Burleson \& Planalp, 2000). This is intrinsically related to anxiety within communication situations. In a 1998 study involving communication apprehension and its relation to social and personal consequences, the researchers found that social anxiety and fear of non-acceptance by peers and audience can bring about serious difficulties in communicating (McCroskey \& Beatty, 1998). Other research has shown relationships between emotions and message production, cognitive processes, expression, and recognition of the emotions of others 
(Burleson \& Planalp, 2000). Many of the concepts mentioned here are direct or indirect components of emotional intelligence.

Before emotional intelligence is examined, a working and agreed upon definition of intelligence must also be explored. Most scholars of intelligence, and emotional intelligence, agree that intelligence is a goal directed, mental activity, marked by efficient problem solving, critical thinking, and effective abstract thinking (Salovey \& Mayer, 1990). They also agree that intelligence comprises the mental abilities necessary for adaptation to environmental contexts (Pfeiffer, 2001). The concept of emotional intelligence combines the mental and logical components of intelligence with the attributes of a constructive and aware emotional arsenal (Goleman, 1995). These components come together most saliently in the communication during conflict situations. Arousal is heightened during times of conflict and emotions are running high. It is at these points where the intersection of cognitive reasoning and emotion are most crucial. Emotional intelligence, the first emotion-based trait focused on in this research, is explored in the following section.

\section{CHAPTER 2: Emotional Intelligence}

Many of the definitions and measures of emotional intelligence have evolved from Howard Gardner's work with multiple intelligences. Gardner (1983) advanced the notion that IQ tests were only limited measurements of two intelligence aspects, verbal and mathematics abilities. He postulated seven total intelligences including kinesthetic, musical and most important to this argument, intrapersonal and interpersonal intelligences (Gardner, 1983). Gardner's work caused an embracing of broader views of intelligence. The primacy of cognitive and analytic mental capacities was challenged, 
and the traditional views of intelligence were amended with new social and emotional components, through his research.

Later, Mayer and Salovey (1990) took Gardner's concepts of interpersonal and intrapersonal intelligence and conceptualized emotional intelligence, or EI. They defined EI as a set of skills hypothesized to contribute to the accurate appraisal and expression of emotion in oneself and in others, the effective regulation of emotion in the self and in others, and the use of feeling to motivate, plan, and achieve in one's life (Salovey \& Mayer, 1990). Salovey and Mayer are credited with coining the term emotional intelligence. Their conceptualization of emotional intelligence is consistent with previous research on social intelligence and social competence (Ford \& Tisak, 1983).

Goleman (1995) defined emotional intelligence as containing five sub-categories. Emotional intelligence entails knowing one's own emotions, managing them, motivating oneself, recognizing emotions in others, and handling relationships, a kind of social competence (Goleman, 1995). Research involving emotional intelligence has shown that it can be significantly more important than cognitive or technical abilities in both scholastic and occupational settings (Goleman, 1995). In some studies, emotional intelligence has been shown to be twice as important as cognitive ability when examined along the variables of success and achievement. The higher one goes in an organization the more important emotional intelligence can become (Kemper, 1999). Emotional intelligence has its origins in a different part of the brain than cognitive intelligence. At certain points in the decision-making process, different parts of the human brain assume control. In more emotional situations the amygdala, the emotional control center for the 
brain, takes over the logic and decision making capabilities. Goleman refers to these instances as "emotional hijacking" (Goleman, 1995).

Emotional intelligence research is imperative in interpersonal contexts.

Recognizing and understanding emotional intelligence differences among people can help increase the relationship satisfaction of marital partners, family groups and peer networks (Goleman, 1995). This thesis contends that emotional intelligence plays a major role in romantic conflict and poses a significant influence upon romantic relationship satisfaction.

Research has been conducted on the gender differences in emotional intelligence scores. Emotional intelligence differences across the genders can be witnessed through overall differences in total scores in emotional intelligence measures, or as differences among the components of the trait. Each type of research has contrasting results. Petrides and Furnham (2000) carried out a study on gender differences in measured and self-estimated emotional intelligence, using Mayer and Salovey's (1990) original conceptualization of emotional intelligence called the MSCEIT. Previous studies have shown that in self-report measures involving intelligences there is a self-enhancing bias in men and a self-derogatory bias in women. Petrides and Furnham (2000) found significant gender differences in the social skills factor of emotional intelligence, with females scoring higher. However, they did not find any other differences between the genders in regards to the other traits of emotional intelligence, or in emotional intelligence scores as a whole. The researchers questioned the use of self-report measures (Petrides \& Furnham, 2000). For the purposes of the following research selfreport measures are the best way to get at internal traits that are not directly observable by 
behaviors, and thus will be used here. The use of self-report measures removes the effects of researcher influence on results, and data is more reasonably obtained when the sample is large. This conflicting past research suggests that more focus should be placed on specific measures and the gender differences found in them.

In another study involving gender and emotional intelligence scores, Schutte and Malouff (1998) found significant gender differences in emotional intelligence, with females scoring higher on all three focuses of the measure. This suggests that more research on the gender differences, or lack thereof in emotional intelligence measures must be explored. The second hypothesis (2a) is stated. There will be a significant difference in emotional intelligence scores between men and women in this sample population.

In 2001, Schutte, Malouff, Bobik and Coston studied the relationship between emotional intelligence and interpersonal relations. They performed seven separate studies, looking at empathy, self-monitoring, social skills, cooperation, relations with others, marital satisfaction, and preference for intellectual partners. The researchers found that participants scoring higher on their version of the emotional intelligence measurement were higher self-monitors, more socially adept, higher on empathetic perspective taking, and more cooperative. Most important to the present argument, people scoring higher on the emotional intelligence measure, reported significantly greater marital satisfaction as measured by the 15-item Locke-Wallace Marital Adjustment Test. In the final study, Schutte and colleagues found that the greatest relationship satisfaction was associated with the other person's high emotional intelligence (Schutte et al., 2001). All of these findings suggest that emotional 
intelligence is related to interpersonal worth, satisfaction, and overall relationship maintenance.

Emotional intelligence research brings about a number of questions and insights. How does emotional intelligence relate to other emotion based personality traits and interpersonal conflict? How do all of these relate to overall relationship satisfaction? Studies have been conducted involving relationship satisfaction with emotional intelligence (Schutte et al.,2001), and affective orientation (Booth-Butterfield, BoothButterfield, \& Hinkle, 1998). Research has not been done incorporating emotional intelligence, affective orientation, and relationship satisfaction. The following sections explore affective orientation, the concept's relation to a number of communication constructs, and incorporates conflict as another predictor variable for relationship satisfaction.

\section{CHAPTER 3: Affective Orientation}

"Emotion plays a bigger part in communicative processes then you would ever know from reading the communication research literature" (Planalp, 1999, p.216). This concept of emotion as a major player in interpersonal communication is specifically relevant to issues involving conflict. In 1990, Booth-Butterfield and Booth-Butterfield advanced a concept and measurement of affective orientation. They defined this concept as the predisposition to actively scrutinize, consider and subsequently use one's emotions as guiding information for making decisions (Booth-Butterfield \& Booth-Butterfield, 1998).

Affective orientation, though sharing some conceptual ground with other constructs has distinct value in the communication field. It is important to validate the 
construct before applying it to research endeavors. There are many constructs and subsequent scales that may, on the surface, seem to measure similar items. For example, affective orientation has been compared to affect intensity. Affect intensity involves differences within individuals involving the strength and means of how they experience their emotions. Affective orientation conceptually differs from this variable because it examines subtle differences in affect, not only the intense experiences of emotion (BoothButterfield \& Booth-Butterfield, 1994). Affective orientation has many similar components with Alexithymia, a psychological construct, studied mainly in the field of Psychiatry. Alexithymia is the "Inability or lack of motivation to communicate affect" (Johnston, Stinski, \& Meyers, 1993). This construct deals with inability or lack of motivation, not precisely with the thought process and utility of emotion as affective orientation does.

The underlying factor for affective orientation involves the same underlying factor for all communication, information processing. Information may be processed using reason and logic, or through feelings and emotions. Cognition and emotion often compete to control our thoughts and actions (Planalp, 1993). Affective orientation, as a concept, attempts to differentiate between these often opposing, often indistinguishable means of processing. Processing of information involves specific steps. Each step in the communication process directly affects the next, the end result being the creation of an emotion in the mind of the receiver (Dillard, Kinney \& Cruz, 1996). Emotion influences the cognitive process, is a component of the message, and is a necessary tool for managing the cognitive and psychological states of others (Burleson \& Planalp, 2000). Emotional processing places higher value on emotional outcomes, and the emotional 
environment than cognitive processing, which deals with facts and logical outcomes. At extremes, cognitively oriented people will discount their emotions entirely, opting for a more logical, and fact based assessment of the situation, whereas affectively oriented people will recognize, define and consider their emotions when making any communication decision (Booth-Butterfield \& Booth-Butterfield, 1990). This commentary on emotion and communication sets the stage for the influence of both affective orientation and emotional intelligence on conflict and relationship satisfaction in romantic relationships.

Affective orientation involves two key components, awareness and action. The first component consists of being aware of your own emotional states. Awareness of emotions can be linked to experience, social norms, and schema development within the individual. For example, people with a more developed schema for emotions will have highly differentiated patterns and definitions for the emotions that they experience. They will be aware of subtle differences in their emotional states, and be able to define those differences with ease. The other component of affective orientation is action. Affective orientation involves not only being aware of your emotions, but also being able to use those emotions in communication situations. Using emotions as a guide for information conceptually differentiates affective orientation from other constructs such as emotional sensitivity and need for cognition (Booth-Butterfield \& Booth-Butterfield, 1990).

Gender and psychological sex differences such as masculinity and femininity have effects on many personality constructs. Affective orientation is one of the constructs influenced by these variables. There is a significant difference between men's scores and women's scores on the affective orientation scale. Women score consistently 
higher than men. There is also a correlation between affective orientation scores and masculine and feminine characteristics. Persons who claim to possess more masculine characteristics will score lower on the scale than people who claim to have more feminine aspects to their personality (Booth-Butterfield \& Booth-Butterfield, 1990). Thus hypothesis $2 \mathrm{~b}$ is proposed, there will be a significant difference between males and females regarding the affective orientation measure.

A Booth-Butterfield and Booth-Butterfield (1990) study assessed correlations between affective orientation and other closely related constructs like conversational sensitivity, femininity, self-monitoring, and communication apprehension. These correlations or lack of correlations are performed to distinguish and differentiate affective orientation from similar constructs. In this original study there were no strong correlations between affective orientation and the need for cognition, masculinity, femininity, communication apprehension, conversational sensitivity, or self-monitoring. The two variables that moderately correlated with affective orientation were femininity and conversational sensitivity. Though these are only moderate correlations the results show that certain personality variables will be conceptually closer to affective orientation than others. The bottom line is that affective orientation is conceptually different from many other communication constructs that have been looked at in the past (BoothButterfield \& Booth-Butterfield, 1990).

The third and fourth studies in this original (1990) publication deal with behavioral references to application of the affective orientation concept. These two studies involved the recall of emotions, emotional terms, the recall of specific situations in which emotions were used in making a decision, and the encoding of those recalls to a 
researcher. The results of these validation studies were mixed. They found that highly affectively oriented individuals had more emotion recall. However the recall and recoding of the communication instance was not significant. The accuracy and clarity of participants emotion recall varied along affective orientation scores, such that individuals with higher affective orientation were able to recall more emotions with greater accuracy, and lower affect oriented individuals were not able to recall as many (Booth-Butterfield \& Booth-Butterfield, 1990). These findings may relate to relational maintenance, and past history as it influences conflict tactic choice. Higher Aos will be able to recall the emotions involved in previous conflicts more clearly and may use those experiences to govern their behavioral choices. Low Aos may not recall the emotions of past conflicts as clearly, and thus may not use them in making a conflict tactic choice.

Affective Orientation has been operationalized in two separate scales. The original measure, which is being employed in the proposed research, contained 20 items. However, it was recognized that valuing emotions and using them in communication situations were very different concepts. The original scale was modified into a 15 -item scale. The key to this modification was looking not at how people view emotions, but if and how they scrutinize them and consider them when making decisions. The original scale was reduced to a fifteen-item Likert-style questionnaire, called the AO15 (BoothButterfield \& Booth-Butterfield, 1996). Researchers now have the choice of scales. If they are studying a wide variety of emotional constructs they may want to use the original scale. However the AO15 as it has been termed is the more preferable measure because it gets at the concept more directly (Booth-Butterfield \& Booth-Butterfield, 1998). 
Beyond the original conceptualization of affective orientation, the two versions of the AO scale have been used a number of times across a variety of different contexts. From humor to intercultural situations, affective orientation can be used to determine the influence and effect of emotions on and within communication.

In the same year that the original affective orientation scale was published (1990) Frymier, Klopf, and Ishii (1990) did a study comparing gender, affective orientation and cultural differences between American and Japanese participants. The results of this study showed that the same gender differences occurred for Americans, with males scoring significantly lower than females (Frymier, Klopf \& Ishii, 1990). This research suggests that there are overall gender differences between American men and women in affective orientation. The original affective orientation scale was used in this study, and since the original is also used in the following research the same gender differences may be expected.

In 1994, Booth-Butterfield and Booth-Butterfield made further conceptual and empirical distinctions in affective orientation. They again compared affective orientation and conceptually related constructs to get at the convergent and divergent validity of the construct. Affective orientation was compared with affect intensity, blunter-monitor emotional style, extroversion, introversion, neuroticism, self-consciousness, and romantic beliefs. The results of this study showed, as in the 1990 study, that most of these concepts differ significantly from affective orientation with alpha's higher than .8 , and all exceed the stated differentiation quotient in the article of .50. The second study in this article got at the reliability or consistency of the affective orientation scale. This study utilized test-retest reliability. Again the reliabilities and validities were similar to those 
found in the original study. The scale was administered to a group of students in a large eastern university at separate times. There was no discussion of the construct between these times. The sample size was 77 . The alpha reliabilities were higher than .80 at both times though gender differences were still present (Booth-Butterfield \& BoothButterfield, 1994).

In 1993, three studies looked at the correlations between affective orientation and comforting (Dolin \& Booth-Butterfield, 1993), nonverbal sensitivity (Booth-Butterfield \& Andrighetti, 1993), and assertiveness (Booth-Butterfield \& Andrighetti, 1993). There was no correlation, .00 , between affective orientation and assertiveness, and moderate correlations between $\mathrm{AO}$ and nonverbal sensitivity, $\mathrm{r}=.45$, and comforting, $\mathrm{r}=.19$. From these findings it can be concluded that affective orientation differs from other constructs significantly but can also be used to predict and support other communication variables

Wanzer, Booth-Butterfield, and Booth-Butterfield (1995) found a moderate correlation, .26 , between affective orientation and humor orientation. People that are high in humor orientation are more likely to be aware of their emotions and use them as guiding information. The probability in this study was .0008 (Wanzer, Booth-Butterfield $\&$ Booth-Butterfield, 1995). Based on much of the aforementioned research, affective orientation can be related to a number of different constructs. The current argument proposed a significant positive correlation between affective orientation and emotional intelligence (Hypothesis 1).

In another 1995 study, Yelsma found affective orientation moderately correlated with expression of negative emotions, $r=.30$, but only slightly correlated with expression of violent emotions, $r=.14$. From this he concluded that affective orientation may be 
related to the expression of negative emotions but cannot be used to predict abusive behavior between spouses (Yelsma, 1995). This study directly relates to the research on conflict and violence in interpersonal relationships as defined in the preceding sections of this proposal. Affective orientation is related to the expression of negative emotions. That expression may cause conflict. The question arises, do more highly affectively oriented people experience more conflict in their interpersonal relationships than low affectively oriented individuals?

Most recently, Booth-Butterfield, Hinkle, and Booth-Butterfield (1998) conducted a study involving satisfaction and affective orientation in interpersonal relationships. The researchers found that affective orientation was more closely associated with individual satisfaction rather than relationship satisfaction. They also found differences in affective orientation and its influence in romantic vs. platonic relationships, such that participants with higher affective orientation showed higher relational adjustment and satisfaction in romantic than in non-romantic or platonic relationships (Booth-Butterfield, Hinkle, \& Booth-Butterfield, 1998). These results suggest that affective orientation has more influence over individual satisfaction than relationship satisfaction. The following research expanded on these findings, explore conflict in romantic relationships, and end the literature review with an examination of relationship satisfaction.

\section{CHAPTER 4: Conflict}

Conflict is an inevitable part of all human association, and is inherent in all close interpersonal interaction (Coser, 1956; Gottman, 1979). There is controversy over the nature and necessity of conflict, within the fields of communication, sociology, and psychology. Some scholars, like Straus (1990) and Stets (1990a,1990b), argue that 
conflict is a necessary component for the development and maturity of a relationship. Without the changes brought about by conflict, interpersonal relationships run a high risk of failure and collapse (Straus, 1990). Some people fear conflict and do whatever they can to avoid conflict situations, especially with their significant others. Intimacy, highly associated with romantic involvement, is directly related to conflict. The more intimacy one has with another, the greater the possibility for conflict (Billingham, 1987; Braiker \& Kelley, 1979). However, if conflict is suppressed, there is a high risk for the accumulation of hostility and the eruption of violence. Straus hypothesizes that conflict and relationship survival relate in a curvilinear fashion. At the extremes where there is no conflict, and excessive conflict, the relationship will fail. In the center, where conflict is moderate and dealt with, the relationship will be at its optimum status (Straus, 1990).

Conflict occurs in all types of romantic and platonic relationships (Argyle \& Furnham, 1983). Interpersonal scholars have defined conflict on a number of different levels. Conflict has been defined as hostility, disagreement, and violence. Failure to distinguish between these many varying levels of clarity makes much of the research on conflict confusing. However some interpersonal scholars have advanced definitions that are both broad enough to be realistic and specific enough to relate to the proposed research. Detusch (1973) defined conflict as the existence of incompatible activity wherein the behavior of one individual in a relationship prevents, obstructs, or makes less likely or effective the behaviors of the other. For the purposes of the proposed research, conflict is defined similarly, as occurring when individuals seek to live out their lives in occurrence with personal agendas that inevitably differ (Straus, 1990). 
Conflict can in many ways endanger and end a relationship, but not all conflicts threaten the continuance of an intimate relationship. Only conflicts over the fundamental basis of a relationship are significant enough to cause threat to the union (Roloff \& Cloven, 1994). It is the nature of the conflict strategies employed by the individuals in the interaction and the means of managing that conflict which sustains or ends the relationship.

Conflict is not a situation to strive for. On the contrary, interpersonal researchers stress the need for effective and competent communication as a means of confronting and managing conflict (Straus \& Gelles, 1990). Competence perceptions mediate the link between conflict messages and relational outcomes (Canary \& Spitzberg, 1989). Perceptions of personal competence and the competence of the other person involved is key to how a conflict will be managed and if that relationship will survive. Communication competence is a relationship skill.

Conflicts can be managed and resolved by the application of the appropriate communicative and behavioral skills. The lack of these skills can bring about the demise of both platonic and romantic relationships (Sillars \& Weisberg, 1987). Communicative skill level and communicator competence both directly influence conflict in romantic relationships. People prefer to communicate with others that have similar skill levels to them. This means that people with lower skills for dealing with conflict, would prefer lower skilled people to higher ones (Burleson \& Sampter, 1994). It is the position of the following research that conflict is present in all interpersonal relationships, both platonic and romantic, and that conflict is influenced by emotion-based communication traits and in turn influences romantic relationship satisfaction. 
Personality traits, and trait measures, quantify people's individual differences. Differences in people's needs, desires and expectations bring about conflict in interpersonal interactions. Conflict that can occur because of these transgressions may include threats to autonomy, individual differences, lack of support, withdrawal, infidelity, not sharing time, loss of romance, not being treated equally, loss of trust, and being critical of the relationship or the relationship partner (Roloff \& Cloven, 1994). Conflict may also occur because of threats to integrity, competence attacks, jealousy, threats of physical harm or violence, incompetence of the other person, and impotence or the inability to comply with the other person (Cupach \& Canary, 1995). Conflict may also arise from interdependence, violations in the expectancies for interaction and influence of the other partner (Peterson, 1983). These causes of conflict get directly to the foundation of a romantic relationship.

\section{Processing of Conflict}

There are many ways in which the processing of conflict has been examined. Buysse, De Clercq, Verhofstadt, Heene, Roeyers, and Van Oost (2000) examined the cognitive processing of conflict. These researchers contend that conflict processing can be looked at through three different methods. The two ways that have been employed by most conflict researchers in the past were self-reports and behavioral observations. Buysee and colleagues used an information-processing paradigm, which looks at how specific messages were received and interpreted by the people in conflict situations. The researchers wanted to know how the information was received and how the cognitive processes and motivation of the individual influenced conflict behavior. They found consistencies with previous self-report and observational research findings. Avoidance 
and distraction from unexpressed relationship thoughts and feelings were prevalent in conflict situations. They also found sex-differences in the cognitive processing of conflict messages. The use of information processing provided new insight into the encoding and decoding of conflict messages. However, the authors did not discount the use of self-report measures in conflict research. Specifically, self-report measures give insight into experiences, beliefs, feelings, attitudes, and perceptions of conflict behavior (Buysse, et al., 2000). The current research proposes the use of self-report measures to determine how emotion-based personality traits are related to perceived conflict tactics and subsequent relationship satisfaction.

To this point, conflict has been defined and possible sources of conflict have been identified. Now this argument will examine how individuals view conflict and how that perspective influences behavioral choice in conflict interactions. At times conflict over important issues is manifested in indirect ways. Partners may engage in conflict with one another, but not necessarily over the same issues (Cupach, 2000). For example a disagreement or conflict over cooking a meal, on the surface is a simple disagreement over food preparation, but may truly be a conflict over the roles and rules of the relationship (Cupach \& Canary, 1995). Perceptions of intentions and responses to the behaviors of the other person in the relationship are both related to emotional intelligence and affective orientation. Though conflict over dinner may not seem to be a direct threat to the stability of a relationship, it points to one of the major issues in interpersonal relationships, power and control. People with high emotional intelligence would understand the emotions surrounding power and control in a relationship. They would be aware of their emotions, and the emotions of their significant other. Highly emotionally 
intelligent people will know what they want and what is most important to their significant other in regards to their emotions and personal needs. They would know how to manipulate situations so that they would be in the emotional position that they prefer. They may use conflict tactics to get at what they most desire, and what most closely meets their emotional needs.

Power structures, which encompass roles and rules, can be considered expectations, which directly relates to the theoretical background of this examination. Culture and society create ideas of how relationships are supposed to be. Stereotypes of masculine and feminine roles, especially during conflict, are present overtly or covertly in many relationships. Women are often expected to be kind, nurturing, sensitive, warm, and expressive. When in conflict, they are expected to be emotionally needy and may resort to tears and other affective displays. Men are expected to be more reasonable, less emotional, more competitive, and task oriented (Deaux \& Lewis, 1984). These stereotypes predict that women will try to be more cooperative and emotional in conflict situations, and men will be more competitive and reasonable. Power structures, roles, rules and stereotypes influence individual perceptions of people in conflict situations. How individuals perceive conflict has a direct affect on how competent they see themselves and their partners to be, and affects what the conflict is attributed to (Canary \& Spitzberg, 1990).

Research exists that counterpoints these stereotypes in interpersonal relationships. Canary and Hause (1993) found that men and women react similarly in conflict situations, and that sex differences do not affect the social behaviors of persons in conflict (Canary \& Hause, 1993). Other researchers also found that men and women 
react similarly in conflict management tactics (Bell, Chafetz, \& Horn, 1982; Metz \& Rosser, 1994; Sternberg \& Soriano, 1984; Zammutto, London, \& Rowland, 1979). The differences found in these research findings leads to the question, as to whether there are sex differences in conflict strategies (Hypothesis 2c)?

Causes of conflict and conflict processing have been examined. The final aspects of conflict in interpersonal communication that will be covered in this review of past research are relational maintenance and conflict management through the use of conflict tactics. Conflict has a number of causes and can be interpreted in many ways, but the key to relationship satisfaction, and overall relational sustenance, is determining how the conflict is managed within the context of the maintained relationship. Conflict tactics, the way in which the conflict is managed, is the main focus of the proposed research.

Conflict tactics can be used for relational maintenance purposes. Relational maintenance involves people in a relationship doing what they can to avoid placing the relationship into any harm. It is a limiting of threats and challenges to the relationship, without regard for individual needs and desires. These practices are performed by one or both people in the relationship in order to prevent threats to a relationship, or to overcome the threats that have been made to that relationship. Talk is the essence of relational maintenance (Duck, 1994). Communication is essential to the sustaining of a relationship over time. Relationships are in a constant state of change, skills in dealing with change and challenge are necessary for success. Maintenance strategies are different and perform different functions in the varying stages of relationships (Shea \& Pearson, 1986). Maintenance approaches include retribution, reformation, prevention, minimization, and relational justification (Roloff \& Cloven, 1994). 
Conflict is an example of a threat to a relationship that must be managed. The way in which conflict is dealt with affects relational maintenance. Relational transgressions, or violations, are perceived and dealt with in different ways depending on the types of relationships in which people are involved. The way in which conflict affects a relationship, and subsequently the types of maintenance approaches used, may be the result of the type of conflict tactics employed in the conflict interaction.

Conflict style is related to relationship satisfaction. Negative conflict styles are significantly associated with relationship satisfaction within conflict situations themselves, or when conflict is left unresolved in a relationship (Cramer, 2000). This research implies that how people deal with conflict, what influences their behavior, and how they choose to behave in conflict situations has a direct effect in relationship satisfaction. The position here is that communication during conflict interactions is the key to having sustained and satisfied relationships. Emotion influences conflict tactic choice and subsequently relationship satisfaction. Conflict tactics are the key components of conflict interactions that influence relationship satisfaction. The specific causes and effects of a conflict are not as influential as the means through which the conflict was dealt with. The initial purpose of the proposed research is to determine the influence of emotion-based personality traits on the choice of conflict tactics employed in romantic relationships. The second purpose is to determine gender differences in emotional intelligence, affective orientation, and the choice of conflict tactics. The final purpose is to examine how all of these factors relate to overall relationship satisfaction.

The final section in the rationale and literature review for this research involves the outcome variable of relationship satisfaction. This concept has been related to each 
of the previous variables in specific and isolated studies. It is the goal of this research to see how all of the traits, emotional intelligence, affective orientation and conflict tactic choice interact to influence relationship satisfaction. This last section discusses relationship satisfaction and leads up to the final and most poignant hypotheses involving all of the constructs in the argument.

\section{CHAPTER 5: Relationship Satisfaction}

Relationship satisfaction has been studied by a number of scholars across many disciplines, though not without question. Relationships are in a constant state of change, and because of this, measures assessing relationship satisfaction do so for only one specific moment in time. However, knowledge of this limitation, and recognition of it, allows for progressive and pervasive study of this topic (Erbert \& Duck, 1997). Relationship satisfaction is studied in the following research because it is a telling outcome variable in romantic relationships. Satisfaction gets at many of the successful skills in communication and the unsuccessful behaviors of human nature.

By definition, relationship satisfaction involves the subjective feelings that a relationship provides more rewards than costs and that the accumulation of positive outcomes is better than what can be expected from other relationships that are similar (Rusbult, 1983; Rusbult, Drigotas, \& Verette, 1994). Relationship satisfaction is an important, complex, and multi-dimensional aspect of intimate romantic relationships (Meeks, Hendrick, \& Hendrick, 1998). In essence, relationship satisfaction is happiness in a relationship. Note, from this definition that satisfaction is highly dependent on individual perceptions of costs and benefits from the relationship. From this one can argue that relationship satisfaction is dependent on a number of personal beliefs about 
oneself and about the behaviors of their significant other. As will be discussed, emotional intelligence, affective orientation and conflict tactics all fit into this working definition as precursors and predictors of relationship satisfaction.

Communication skills involving affective disclosure are strong indicators of relationship satisfaction, affect is key to relationship satisfaction (Anderson \& Guerrero, 1998; Canary \& Cupach, 1988). Affective orientation and emotional intelligence may fall under this rubric, but what about other traits? Companionship, sexual expression, and supportiveness are related to relationship satisfaction. People who show greater interest in companionship, physical interest and provide support for their significant other have higher overall relationship satisfaction (Sprecher \& Metts, 1995). More skilled communicators that have greater love orientation, experience greater relationship satisfaction (Meeks, Hendrick, \& Hendrick, 1998). Conscientiousness and agreeableness, positive aspects of psychoticism (social desirability) are reliably related to satisfaction in dating relationships (Watson, Hubbard, \& Wiese, 2000). This means that the more predisposed an individual is to pay attention to relationships and how willing they are to compromise are related to how satisfied they are in their relationships.

Outside of individual personality and perceptual differences, there are some gender differences in overall relationship satisfaction. Women's commitment to heterosexual relationships is strongly correlated with relational satisfaction. Inequality of contributions in a relationship very often leads to relationship dissolution. If women give too much and men little this is the detrimental to relationship satisfaction (Sprether, 2001). Women are the barometers for the health of a relationship (Kiecolt-Glaser \& Newton, 2001). This research implies that men and women experience relationships in 
different ways and that their satisfaction in those relationships will be contingent on different variables. Relationship satisfaction is a combination of self-perceptions, and both the overt behaviors and the perceptions of those behaviors (Davis \& Oathout, 1987; Murray, Holmes, \& Griffin, 1996).

In sum, emotions play a strong role in interpersonal communication. Specific personality traits are related to how people perceive their own emotions, the emotions of others, and how people act on those perceptions. Emotional intelligence has been related to relationship satisfaction. Higher emotionally intelligent people have greater overall relationship satisfaction, and prefer partners with higher emotional intelligence (Schutte, et al., 2001). Affective orientation has been related to individual satisfaction in both platonic and romantic relationships (Booth-Butterfield, Hinkle, \& Booth-Butterfield, 1998). This research has shown that emotion-based personality traits reflect the degree to which emotions can affect the way in which a person thinks about and understands relationships, feelings, and how people behave because of those feelings. Conflict tactics are specific behaviors and enactments in romantic relationships. Verbal aggression, and reasoning tactics are two examples of behaviors that may influence the relationship satisfaction. How emotions are perceived and decisions that are based on emotions in romantic relationships influences overall satisfaction. The choice of conflict tactics affects relationship satisfaction (Cramer, 2000). This research examines the aforementioned traits in conjunction with one another. The goal of the research was to understand how emotion-based personality traits, in this case, emotional intelligence and affective orientation, influence the choice of conflict tactics in romantic relationships, and how that choice affects the overall relationship satisfaction of the individuals involved. 
The following hypotheses and research question were proposed based on the aforementioned arguments and premises.

\section{CHAPTER 6: Hypotheses and Research Question}

H1: There is a significant positive correlation between emotional intelligence scores and affective orientation scores.

H2: There are significant gender differences in (a) emotional intelligence scores, (b) affective orientation scores such that females will score significantly higher on both measures, and no gender differences in males and females use of (c) conflict tactics.

H3: Emotion-based personality traits will be related to conflict tactics such that:

a. Highly emotionally intelligent individuals will use more reasoning conflict tactics than verbally aggressive tactics.

b. Low affectively oriented individuals will use more reasoning conflict tactics than verbally aggressive tactics.

H4: Emotion-based personality traits in conjunction with the choice of conflict tactics can be used to predict relationship satisfaction, in that persons with higher emotional intelligence, higher affective orientation, using more reasoning than verbal aggression tactics will have greater overall relationship satisfaction.

RQ: Which variable best predicts relationship satisfaction, emotional intelligence, affective orientation, or the choice of conflict tactics?

\section{CHAPTER 7: Method}

Sample Population

The target population for this research was college students. College students have a number of different relationships, and as a population, would be at different levels 
in their relationships. College is a time of change and it is arguably the time in which relationships are most diverse and complex. These desired qualities made a college population the most reliable source. Participation in this study was voluntary.

\section{Procedures}

The research was conducted through the distribution of a survey style questionnaire. The measures were given to an undergraduate communication studies class from a large Mid-Atlantic university. The participants filled out a questionnaire based on their own emotion-based traits, the conflict tactics that they use, and the conflict tactics that their partners use. Specific conflict situations were not examined. Conflict was looked at along the lines of frequency, and type of conflict. The participants also completed a measure that assessed overall relationship satisfaction. The questionnaires were administered during class, and were returned to the researcher upon completion.

\section{Measures}

The first measure in this study is an emotional intelligence measure. Emotional intelligence is the ability to perceive and express emotions, to understand and use them, and to manage them so as to foster personal growth (Salovey, Mayer, Caruso, \& Lopes, 2001). A number of emotional intelligence measures have been advanced since its conceptual beginnings. Salovey and Mayer put forth a measure of emotional intelligence called the MSECIT, Bar-On advanced the EQ-I (Bar-On \& Parker, 2000), and Schutte and Malouff (1998) advanced a self-report scale based on the concepts of Mayer and Salovey. The MSECIT measures emotional perception and the EQ-I measures interpersonal competencies, self-regard, and assertiveness (Salovey, Mayer, Caruso, \& Lopez, 2001). Mayer, Caruso, and Salovey (2000) assert that one of the key components 
of researching emotional intelligence is choosing which factors of emotional intelligence you want to focus on (Mayer, Caruso, \& Salovey, 2000).

The following research uses a 33-item likert scale response questionnaire, created in 1998 by Schutte and Malouff. It was chosen for the following research because it is a self-report measure, like the other measures involved in the research. The measure is brief and gets at the same basic ideas that the other measures of emotional intelligence, but it does not involve the researcher in interviewing the participants. The emotional intelligence measure used in this questionairre is a Likert-style measure with answer categories ranging form 1-strongly disagree to 5-strongly agree with a neutral category in the middle. This measure is scored by recoding items 5 and 33, and totaling the responses to all questions. The higher the total score, the greater the participant's emotional intelligence. Examples of items from this measure include, "I expect good things to happen," and "I know why my emotions change." Scores on this scale range from 33-165. In previous studies the scale obtained reliabilities spanning .86 to .92 (Schutte, Malouff, \& Hall et. al., 1998; Schutte, Malouff, Bobik et. al., 2001) (See Appendix A).

The second measure in the survey is the affective orientation measure. Affective orientation is the predisposition to actively consider, scrutinize and subsequently use ones emotions as information in making decisions. This measure is a twenty-item, Likertstyle, self-report questionnaire with five answer categories ranging from 5-strongly agree to 1-strongly disagree. In previous studies the affective orientation scale obtained reliabilities of .83 to .92 (Booth-Butterfield \& Booth-Butterfield, 1994). This measure is scored by recoding the necessary items and totaling the responses to all of the items. The 
higher the participants total score, the more affectively oriented they are. Items on this measure include statements like "my emotions tell me what to do in many situations," and "I try not to let feelings guide my actions." (See Appendix B).

Conflict tactics will be measured through the Conflict Tactics Scale used in the 1985 National Family Violence Survey (Straus \& Gelles, 1990) (See Appendix C/ Appendix D). The CTS is the most widely used instrument for research in interpersonal violence. This scale reduces the infinite number of possible tactics used in conflict interaction to three specific categories. These are rational discussion, which involves argument and reasoning; the use of verbal and nonverbal acts, which may be hurtful to the other person; and the use of physical force against the other person (Straus, 1990). The CTS can be used in assessing conflict in any of the following relationships; husbandwife, wife-husband, father-child, child-father, mother-child, child-mother, child-sibling, sibling-child. In this research the CTS is used to obtain information on participant's use of verbal aggression and reasoning tactics in the romantic relationships they are currently in. The questionnaire also measures the participant's perception of the types and frequency of tactics that their romantic relationship partner uses.

As with any self-report measure, the CTS has limitations and benefits. Critics contend that measures of conflict in marital and romantic relationships underplay the occurrence of violence in interpersonal relationships. Feminists criticize these measures because their findings show that women enact the same if not more violence in interpersonal relationships that men do, only men are less likely to report these occurrences due to cultural and societal norms (Stets \& Straus, 1990a). Critics also assert that scales like these do not account for other types of violence, and that threatening 
behavior is labeled as violent behavior. It is also their position that the person whom initiates the conflict is not identified, nor is the context of the conflict identified, and this is a limitation for the measures and the data obtained (Straus, 1990).

The benefits of using the conflict tactics scale are numerous as well. The scale is a simple Likert style self-report measure. People are less likely to report violence during interviews due to social desirability factors, and interviewer effects. The anonymous self-report measure can get at violence more directly than interviewing. Second, the CTS seperates specific and differing tactics into three categories, reasoning, verbal aggression, and physical violence. Two of the three categories measured by the CTS will serve as comparison sub scales with the two personality traits of emotional intelligence and affective orientation as well as the outcome measure of relationship satisfaction.

Perhaps most importantly, the CTS has been used in over 100 research studies allowing greater comparability of results. These studies range from conflict and violence within the family (Straus, 1990) to conflict comparisons across dating, married, and cohabitating couples (Stets \& Straus, 1990b). For the purposes of this research, the conflict tactics scales involved with the romantic relationship of wife-husband and husband-wife will be applied to the romantic relationships in college students. The violence items have been excluded from this study in order to focus the findings into reasoning and verbally aggressive tactics. Some more reasoning items have been added to the scale (See * items, Appendix C/D). The result is a 15 item Likert-style questionnaire, responded to based on the participants' qualities and the same items directed at the qualities they perceive in their significant other, totaling 30 items addressing the couples conflict interactions. This measure is scored by recoding the 
necessary items, and adding up the scores of the subscales. The higher the score on the subscale the more frequent use of that type of conflict tactic. Items on this scale include behaviors like yelling, crying, and compromising (See Appendices C and D). For the purposes of the current research the conflict tactics scale was broken down into four components, participant conflict tactics of verbal aggression (SCTVA), participant conflict tactics of reasoning (SCTR), partner conflict tactics of verbal aggression (PCTVA), and partner conflict tactics of reasoning (PCTR).

The final component of this research involves a relationship satisfaction scale. Much of the research cited here used a variety of measures to assess relationship satisfaction, but across relational research, the most often used scale is Spanier's 1976, dyadic adjustment scale (DAS). This scale builds upon over 150 empirical studies exploring marital adjustment. The questions are rated on a number of different types of response options, Likert-style, semantic differential, one yes/no answer category question, and one statement selection that best describes your relationship happiness. This scale can be divided into four sub categories, dyadic consensus, dyadic cohesion, dyadic satisfaction, and relationship affective displays. The total score for the scale represents overall dyadic adjustment (Spainer, 1976). Two questions have been left off the original scale that inquired about drug use and sexual activity. This leaves thirty items. The items address the topics that people disagree upon, what the couple most often discusses, behavioral elements that the couple engages in, overall happiness, and general feelings about the relationship. Some example items include "how often do you laugh together," and "how often do you disagree over career decisions?" For the current research, the dyadic adjustment scale was examined in two ways, based on its subscales, 
and total relationship adjustment. As previously mentioned, the four subscales are dyadic consensus (RSDCON), dyadic satisfaction (RSDSAT), dyadic cohesion (RSDCOH), and affective displays (RSAFF).

\section{CHAPTER 8: Results}

Descriptive Statistics

159 participants completed the measures compiled for this research, (84 men, comprising $52.8 \%$ of the total sample, and 75 women, the remaining $47.2 \%$ of the sample). Relationship length, though not a variable under study in this research, was also reported. Relationships ranged in duration from one month to 72 months, with an average relationship length of 19.2 months, roughly a year and a half. The standard deviation for relationship duration was 17.88 months.

In the current research, the emotional intelligence scale resulted in a reliability of .86 , with a range of 93-151, a mean score of 120.00, and standard deviation of 11.67. The affective orientation scale resulted in a reliability of .89, with a range of 41-96, mean score 74.79, and standard deviation of 9.74. Conflict tactics were measured for both the participant and the participant's perceptions of their significant others' use of conflict tactics. Participants' use of verbal aggression tactics (SCTVA) resulted in a reliability of .65 , with a range of 7-26, a mean score of 14.31, and standard deviation of 3.45 . Participants' use of reasoning tactics (SCTR) resulted in a reliability of .42, with a range of 20-38, a mean score of 30.58, and a standard deviation of 3.10. Participants' perceptions of their significant others' verbal aggression tactics (PCTVA) resulted in a reliability of .68 , with a range of $8-25$, a mean score of 14.42 , and standard deviation of 3.93. Participants' perceptions of their significant others' use of reasoning tactics 
(PCTR) resulted in a reliability of .62, with a range of $16-37$, a mean score of 27.58 , and standard deviation of 4.38 (See Table 1).

In this research, the dyadic adjustment scale (DAS) was examined in two ways, based on its subscales, and total relationship adjustment. As previously mentioned, the four subscales are dyadic consensus (CON), dyadic satisfaction (SAT), dyadic cohesion $(\mathrm{COH})$, and Affective displays (AFF). CON subscale obtained a reliability of .85, with a range of 22-77, a mean score of 56.76, and standard deviation of 8.72. SAT subscale obtained a reliability of .89 , with a range of $14-61$, and a mean score of 46.74 , and standard deviation of 8.43. $\mathrm{COH}$ subscale obtained a reliability of .74, with a range of 830, a mean score of 22.48, and standard deviation of 3.87. AFF subscale obtained a reliability of .43 , with a range of $3-14$, a mean score of 11.14 , and standard deviation of 1.95. The total dyadic adjustment is obtained by cumulating the four sub-scales. The DAS, total dyadic adjustment, achieved a reliability of .92, with a range of 70-180, a mean score of 137.1, and standard deviation of 19.39 (See Table 1).

\section{Tests of Hypotheses and Research Question}

Hypothesis one predicted that there would be a significant positive correlation between affective orientation and emotional intelligence scores. Results of a Pearson correlation support this hypothesis $(\mathrm{r}=.58, \mathrm{p}<.0001)$.

Hypothesis two proposed that there would be significant differences between males and females on emotional intelligence (a) scores, affective orientation (b) scores, and conflict tactic (c) scores. Gender differences were tested using t-test. Analysis revealed significant differences in females' and males' emotional intelligence scores $(\underline{\mathrm{t}}(157)=-3.55 ; \mathrm{p}<.0005)$ with females' emotional intelligence scores $(\underline{\mathrm{M}}=123.35)$ being 
significantly higher than males ( $\underline{M}=117.00)$, thus supporting hypothesis $2 \mathrm{a}$. The second part of this hypothesis addressed gender differences in affective orientation scores. The analysis revealed a significant difference between males and females' affective orientation scores $(\underline{\mathrm{t}}(157)=-4.77 ; \mathrm{p}<.0001)$ with females' scores $(\underline{\mathrm{M}}=78.44)$ being significantly higher than males ( $\underline{\mathrm{M}}=71.52)$, thus supporting hypothesis $2 \mathrm{~b}$. No gender differences were found in any of the four subscales of the conflict tactics measure $(\mathrm{SCTVA}, \mathrm{p}=.32, \underline{\mathrm{M}}(\mathrm{m})=14.55, \underline{\mathrm{M}}(\mathrm{f})=14.04 ; \mathrm{SCTR}, \mathrm{p}=.42, \underline{\mathrm{M}}(\mathrm{m})=30.77, \underline{\mathrm{M}}(\mathrm{f})=30.37$; PCTVA, $\mathrm{p}=.26, \underline{\mathrm{M}}(\mathrm{m})=14.08, \underline{\mathrm{M}}(\mathrm{f})=14.79 ;$ PCTR, $\mathrm{p}=.14, \underline{\mathrm{M}}(\mathrm{m})=27.11, \underline{\mathrm{M}}(\mathrm{f})=28.12)$, thus hypothesis $2 \mathrm{c}$ was supported.

Hypothesis three examined the ways the two emotion-based personality traits were related to choice of conflict tactics in romantic relationships. Hypothesis 3a stated that people with higher emotional intelligence would use more reasoning tactics than verbal aggression tactics. Results of Pearson correlations showed that emotional intelligence scores were significantly and positively correlated with the participant's use of reasoning tactics $(\mathrm{r}=.26 ; \mathrm{p}<.001)$. Emotional intelligence scores were significantly and negatively associated with participant's use of verbal aggression tactics $(\mathrm{r}=-.22 ; \mathrm{p}<.005)$. Results of these Pearson correlations support hypothesis 3a. Hypothesis $3 \mathrm{~b}$ advanced that people with higher affective orientation would also use more reasoning tactics than verbal aggression tactics. Results of two Pearson correlations showed that affective orientation was significantly and negatively associated with a person's use of verbal aggression tactics $(\mathrm{r}=-.18 ; \mathrm{p}<.05)$. However, correlation between affective orientation scores and participant's use of reasoning tactics was not significant $(r=.13 ; \mathrm{p}=.1)$. Hypothesis $3 \mathrm{~b}$ was not supported by this data. 
Hypothesis four predicted that emotion-based personality traits in conjunction with the choice of conflict tactics could be used to predict relationship satisfaction, in that persons with higher emotional intelligence, higher affective orientation, using more reasoning than verbal aggression tactics would have greater overall relationship satisfaction. This position was tested through a stepwise multiple regression analysis. Relationship satisfaction scores, a subscale of the dyadic adjustment scale, were regressed on the linear combination of four predictor variables, affective orientation, emotional intelligence, participants' use of verbal aggression tactics, and participants' use of reasoning tactics. The equation containing these variables produced a significant model, and accounted for $29 \%$ of the variance in relationship satisfaction $(F(4,155)=$ 15.38, $\mathrm{p}<.0001)$. A closer examination of the beta weights revealed that the participant's use of verbal aggression tactics was negatively related to relationship satisfaction with a beta weight of $-.34(p<.0001)$. Affective orientation was significantly related to relationship satisfaction with a beta weight of $.36(\mathrm{p}<.0001)$. This hypothesis was partially supported. Emotional intelligence scores and participant's use of reasoning tactics failed to obtain significance in the model with p-values of .64 and .55 respectively. In simple correlations emotional intelligence was correlated with all of the variables under study. Correlations ranged from -.22 (participants use of verbally aggressive conflict tactics) to .58 with affective orientation (See Table 2 for simple correlations between variables)

The research question examined which variable would be the best predictor of overall relationship adjustment and satisfaction. This question involved the combination of the four sub-categories of the dyadic adjustment scale into a total satisfaction and 
adjustment variable (DAS). Using multiple regression analysis, the variables were regressed on the linear combination of emotional intelligence, affective orientation, or the choice of the four types of conflict tactics (SCTVA, SCTR, PCTVA, PCTR). The equation containing these six variables accounted for $40 \%$ of the variance in dyadic adjustment $(\underline{F}(6,152)=17.144, p<.0001)$. The model is significant. A closer examination of the beta weights revealed that of the six predictor variables, three were significantly related to dyadic adjustment. Affective orientation, participants perceptions of their partners' verbal aggression, and participants' perception of their partners' reasoning conflict tactics were related to dyadic adjustment with a beta weights of $.30,-.34$, and .24 respectively.

In summary, the two emotion-based personality traits under study emotional intelligence, and affective orientation were found to correlate highly. Males and females differed on both of these emotion measures, with females scoring significantly higher. Higher emotional intelligence was associated with participants using more reasoning tactics, and less verbally aggressive tactics in conflict situations. Higher affective orientation scores were associated with less use of verbal aggression tactics, but no association was found between affective orientation scores and the participant's use of reasoning tactics. Relationship satisfaction can be predicted by participant's use of verbal aggression tactics, their perceptions of their significant others' use of verbal aggression tactics, and the participants' affective orientation scores. Relationship satisfaction was not associated with emotional intelligence and reasoning tactics in the proposed model. In determining the best predictor of overall dyadic adjustment and satisfaction, three variables related to dyadic adjustment. These were affective 
orientation, participants' perceptions of their partners 'use of verbal aggression tactics, and the participants' perception of their partners' use of reasoning in conflict situations.

\section{CHAPTER 9: Discussion}

The primary goal of this study was to determine the relationships among the conflict tactics people use, their emotion-based personality traits, and overall relationship satisfaction in romantic relationships. This research proposed a direct relationship between emotional intelligence, affective orientation, the use of reasoning conflict strategies, and relationship satisfaction in romantic relationships. Findings from this study further describe the role of emotion in interpersonal relationships. Specifically, the researchers discovered that there was a significant strong relationship between affective orientation and emotional intelligence the two emotion traits under study. This research demonstrated that emotional personality traits affect conflict tactic choice and relationship satisfaction in romantic relationships. This study showed that verbal aggression tactics of both the participants' and how the participant perceived the verbal aggressive tactics of their significant others', along with affective orientation and emotional intelligence, were more closely related to relationship satisfaction than were reasoning tactics. Each of these findings will be discussed further in the following.

The results of Hypothesis one in this study indicated a relationship between emotional intelligence and affective orientation. Conceptual similarities between the two constructs may be cited for this finding. Affective orientation is the predisposition to actively consider, scrutinize, and subsequently use one's emotions as guiding information when making decisions (Booth-Butterfield \& Booth-Butterfield, 1990). Affective orientation involves awareness of ones emotions and acting on them. Previous research 
has shown that $\mathrm{AO}$ can be associated with a number of emotional constructs like conversational sensitivity, femininity, self-monitoring, and communication apprehension (Booth-Butterfield \& booth-Butterfield, 1990). Affective orientation has also been correlated with comforting (Dolin \& Booth-Butterfield, 1993), and nonverbal sensitivity (Booth-Butterfield \& Andrighetti, 1993). Emotional intelligence is a set of skills that contribute to the accurate appraisal and expression of emotion in oneself and in others, the effective regulation of emotion in the self and in others, and the use of feeling to motivate, plan, and achieve in one's life (Salovey \& Mayer, 1990). Emotional intelligence has been associated with higher self-monitoring, being socially adept, empathetic perspective taking, and higher cooperative behaviors (Schutte, Malouff, Bobick, \& Coston, 2001).

Many aspects of the conceptual definitions provided here support this relationship. Affective orientation has been associated with many of the same concepts as emotional intelligence. Highly affectively oriented people, and highly emotional intelligent people are high self-monitors. Emotionally intelligent people are aware of their emotions as they occur and use their emotions constructively. Highly affectively oriented individuals will be aware of their emotions, and use them when making decisions, but not necessarily constructively. There is a distinction between these concepts. Emotional intelligence is not, by definition, a pre-determinant of using emotions to make decisions; it is recognition of ones own emotions, as well as the emotions of others. Highly affectively oriented individuals may or may not consider the emotions of others, but may use their own emotions in decision making when the result may be detrimental. In light of these conceptualizations, the findings in this study are not 
surprising and are consistent with previous research relating emotional intelligence and affective orientation to the same if not similar communication and relational constructs (self-monitoring, empathy, and sensitivity). Thus affective orientation and emotional intelligence are highly correlated, but exist separately as conceptually distinct variables. Though the two emotion-based personality traits are highly correlated they are distinct. Emotional intelligence and affective orientation relate to variables differently. The other hypotheses under study show that in certain instances emotional intelligence correlates with variables while affective orientation does not and vice versa. These findings further define the conceptual differences of these two terms.

The second hypothesis predicted gender differences in affective orientation and emotional intelligence, but not in conflict tactics choice. Previous research has been further extended by these findings. Booth-Butterfield, and Booth-Butterfield (1990), found a significant difference between men and women's scores on the affective orientation scale, with women score consistently higher then men. Another 1990 study by Frymier, Klopf, and Ishii also showed the same gender differences occurred, with males scoring significantly lower than females, though this finding was only significant in the sample from the United States and not the sample from Japan. Findings from the current research show similar results. This finding may be related to a number of factors, primarily, that this research utilized the original conceptualization of the affective orientation measure, the $\mathrm{AO} 20$. This version of the scale was modified later to a shorter version, the AO15, which corrected for some of the gender difference. However, it was suggested by the creators of the scale, that when doing research that involved a number of emotion measures the AO20 was more applicable (Booth-Butterfield \& Booth- 
Butterfield, 1996). This finding implies that females are significantly more aware of their emotions and use their emotions more when making decisions. These results are particularly salient in interpersonal relationships where emotions are typically more intense and abundant than in platonic involvements. Knowledge that females are more sensitive to their emotional states should influence the ways in which both males and females communicate with one another in their romantic relationships, with women more likely to react and behave emotionally in relatively non-intense situations than men.

Findings from this study also demonstrated gender differences on trait emotional intelligence, with females scoring significantly higher. Previous emotional intelligence research has also found sex differences involving the trait. Petrides and Furnham (2000) found significant gender differences in the social skills factor of emotional intelligence, with females scoring higher. Schutte and Malouff (1998) also found significant gender differences in emotional intelligence, with females scoring higher on the measure. Thus, findings in this study are consistent with the past research. Females are more likely to have the personality and behavioral components of emotional intelligence. This suggests that females are more likely to be accurate in the appraisal and expression of their own emotions, the expressions of others, effective regulators of emotion in the self, and are more likely to use feelings to motivate, plan, and achieve in their lives than males. This is not to say that males do not possess these abilities. This finding suggests simply that women are more attune to emotional states, emotional recognition, and emotional expression. Implications of this finding are similar to those of the gender differences found in affective orientation results. Higher emotional intelligence increases the influence and role of emotions in communication situations, such that females, higher in 
emotional intelligence will attend to their own emotions, and to the emotions of others more acutely than males who may exhibit the trait to a lesser degree. Importantly, females are more sensitive to emotions, and will make decisions on those emotions. In romantic relationships this tendency is key to understanding why people respond to conflict in certain ways, and how emotions impact the success or failure of romantic relationships.

The last component of hypothesis two contended that there would not be any gender differences in the choice of conflict tactics in romantic relationships. Findings of this study supported this hypothesis. No significant gender differences were found any subscales of the conflict tactics scale (SCTVA, SCTR, PCTVA, PCTR). These findings are consistent with some previous research, and inconsistent with other previous findings. Canary and Hause (1993) found that men and women react similarly in conflict situations, and that sex differences do not affect the social behaviors of persons in conflict (Canary \& Hause, 1993). Other researchers noted behavioral differences between men and women in conflict situations. Women are often expected to be kind, nurturing, sensitive, warm, and expressive. When in conflict, they are expected to be emotionally needy and may resort to tears and other affective displays. Men are expected to be more reasonable, less emotional, more competitive, and task oriented (Deaux \& Lewis, 1984). It is important to note that in regards to the Deaux and Lewis (1984) study the researchers examined expectations of conflict behaviors rather than frequency of actual behavior, which was looked at in the current research. This distinction may be responsible for the inconsistencies noted between these results and past research. 
Interpreting the findings of this hypothesis is somewhat difficult. Findings on gender differences in affective orientation and emotional intelligence would suggest that women would be more attune to their emotions and would use emotions more when making decisions in conflict situations consistent with Deaux and Lewis (1984). Choice of a conflict tactic, verbal aggression, or reasoning, is a behavioral decision, which may be influenced by emotions. This would point to gender differences involving conflict tactics in romantic relationships. However, findings from the current study are consistent with Canary and Hause (1993), and imply that in conflict women and men react similarly. Men do not use more reasoning or verbal aggression tactics than women. Propensity to act in conflict is statistically the same. In this way one cannot make predictions on how people will react in conflict situations based on gender alone, other factors must be considered. It must also be noted that gender may not even play a role in conflict tactics whatsoever. It is also important to note the measurement differences in comparing current and past results. The current study utilized a version of the conflict tactics scale, which was a self-report measure assessing the frequency of certain conflict behaviors. Other previous research employed measures of expected, not actual behavior, which can be noted as a source of this discrepancy.

Hypothesis three proposed a relationship between emotion based personality traits (affective orientation and emotional intelligence) and conflict tactic choice. The finding that higher emotional intelligence was positively associated with the participant's use of reasoning tactics, and negatively associated with the participant's use of verbal aggression tactics is particularly interesting. This implies that people with high emotional intelligence are more likely to employ reason in conflict, and less likely to use 
verbal aggression. This finding supports the general conceptualization of emotional intelligence, which involved careful consideration, not only of one's own emotions, but the emotions of others as well as the context of interaction. This assessment of emotions, done by the more emotionally intelligent individuals more closely resembles logic, perspective taking, and reason than the immediate response of aggression in a highly intense situation. The association of emotional intelligence and conflict tactic choice has not been examined in previous research. The current research provides some insight as to the ways in which conflict and emotional intelligence relate in romantic relationships.

The second component of hypothesis 3 advanced that affective orientation was also associated with the participant's greater use of reasoning tactics than verbal aggression tactics in romantic relationships. Results showed that there was a negative correlation between affective orientation and participant's use of verbal aggression tactics, but the association between affective orientation and participants use of reasoning tactics was not significant. Affectively oriented individuals will respond because of their emotions, not necessarily expressing them. It is tempting to conclude that high AOs will react instinctively and intuitively without rationalizing the feelings of others in interaction, but this would not be consistent with low verbal aggression. It is possible that emotions drive people to react more empathetically and with sensitivity. Previous research has associated affective orientation with self-monitoring, and conversational sensitivity (Booth-Butterfield \& Booth-Butterfield, 1990). These associations would suggest a likelihood of not using verbal aggression as a tactic, and using reasoning instead. Findings from the current study are partially consistent with this idea. AO was negatively associated with verbal aggression conflict tactics, implying that high AOs are 
less likely to use verbally aggressive conflict tactics than low AOs, but the findings on reasoning are inconclusive. The inconclusive findings suggest that just because a person high in affective orientation avoids verbally aggressive conflict tactics, this does not predispose them to advocating or using reasoning tactics. Generally from this hypothesis, higher affective orientation and higher emotional intelligence are linked with less verbal aggression in conflict situations. Increasing emotional awareness and attention, may decrease the likelihood of the occurrence and use of verbally aggressive tactics in romantic conflict. Reasoning tactic use is more highly associated with emotional intelligence than affective orientation.

The fourth and final hypothesis involved relationship satisfaction. Relationship satisfaction for romantic dyads was associated with the participants' affective orientation $(\mathrm{r}=.41, \mathrm{p}<.0001)$, and participants using less verbal aggression tactics $(\mathrm{r}=-.41, \mathrm{p}<.0001)$. Emotional intelligence and the participant's use of reasoning tactics failed to reach significance in the model. Previous research had suggested relationships between both affective orientation and relationship satisfaction, and emotional intelligence and relationship satisfaction (Booth-Butterfield, Hinkle, \& Booth-Butterfield, 1998; Schutte, Malouff, Bobik, Coston, 2001). However, the findings in this study only partially support this link. Previous research (Booth-Butterfield, Hinkle, \& Booth-Butterfield, 1998), determined that affective orientation was positively associated with relationship satisfaction and that participants with higher affective orientation showed higher relational adjustment and satisfaction in romantic than in non-romantic or platonic relationships. Another study involving affective orientation found affective orientation to be moderately correlated with expression of negative emotions, $r=.30$, but only slightly 
correlated with expression of violent emotions, $r=.14$. This is consistent with the link between affective orientation and verbal aggression tactics found in this research. The researcher concluded that affective orientation may be related to the expression of negative emotions but cannot be used to predict "abusive" behavior between spouses (Yelsma, 1995). Verbal aggression may involve an expression of negative emotions, or intent to abuse. Relationships between the current findings and the Yelsma study are speculation, but do provide venues for future research and clarification.

Contrary to previous findings, where emotional intelligence was correlated with relationship satisfaction, (Schutte, Malouff, Bobik, \& Coston, 2001), emotional intelligence was not significant in the model from the current research. Though emotional intelligence was found to correlate with relationship satisfaction $(\mathrm{r}=.26$, $\mathrm{p}<.001)$ in simple correlations, the variable was not a factor in the regression equation. This finding implies that regarding relationship satisfaction, affective orientation is more influential than emotional intelligence, and that perhaps emotional intelligence may not be a factor. The same measurement was used for emotional intelligence in both studies, but the measures for relationship satisfaction were not the same. Schutte et al. (2001) used the 15-item Locke-Wallace Marital Adjustment test. This measure assesses similar concepts as the Dyadic Adjustment Scale (Spainer, 1976), such as spousal agreement, and satisfaction with the relationship. Differences in measurements may be responsible for the contrasting findings.

This study predicted relationships involving emotion trait correlations, gender, conflict tactics, and relationship satisfaction, with additional testing of which factors were the best predictors of overall dyadic adjustment and relationship satisfaction. It was 
reasonable that because these traits have been found to relate to relationship satisfaction in previous research (Booth-Butterfield, Hinkle, \& Booth-Butterfield, 1998; Schutte et al., 2001), addition of more factors to the prediction power would enrich the explanatory power. This research showed that the variables, affective orientation, participant's perception of their significant other's use of verbal aggression tactics, and the participants' perceptions of their partners use of reasoning tactics significantly predicted dyadic adjustment. Negative conflict styles were significantly associated with relationship satisfaction within conflict situations themselves, or when conflict is left unresolved in a relationship (Cramer, 2000). How emotions are perceived and implementation of decisions that are based on emotions in romantic relationships influence overall satisfaction. The choice of conflict tactics affects relationship satisfaction in that the more aggressive the tactic the less satisfied the individual feels in the relationship (Cramer, 2000).

All of these past research findings suggest that verbal aggression conflict tactics (negative conflict styles) would be negatively related to overall relationship satisfaction and dyadic adjustment. Cramer also noted that basing decisions on emotions also influences dyadic adjustment, which is an integral component of affective orientation. It is interesting to note that the correlation obtained here is between relationship satisfaction, dyadic adjustment, and participant's perceptions of their partner's behavior. In past research, relationship satisfaction was related to a combination of selfperceptions, and both the overt behaviors and the perceptions of those behaviors (Davis \& Oathout, 1987; Murray, Holmes, \& Griffin, 1996). This finding suggests that the combination of a person's perceptions of their significant other, and the degree to which 
the person themselves considers their emotions and uses them in making decisions has a direct effect on dyadic adjustment. The failure of emotional intelligence and participant's reports of their own conflict tactics in romantic relationship to be found significant in the model is contrary to previous research. Schutte and colleagues (2001) found that the greatest relationship satisfaction was associated with the other person's high emotional intelligence (Schutte et al., 2001). These researchers found that emotional intelligence was related to interpersonal worth, satisfaction, and overall relationship maintenance. Contrary to this previous research, the current findings suggest otherwise. Emotional intelligence was not, within the proposed model, associated with either relationship satisfaction or dyadic adjustment. The findings of the current research suggest the emotional intelligence, participant's use of verbal aggression or reasoning tactics in romantic conflict, do not influence dyadic adjustment which is highly correlated with overall relationship satisfaction, noting that dyadic adjustment is the combination of the four subscales one of which is relationship satisfaction. Overall the implications of this research finding suggest that affective orientation is one of the key factors in relationship satisfaction, and perceptions of one's significant other also functions as a determinant of dyadic adjustment.

\section{CHAPTER 10: Limitations and Future Research}

This study has a number of limitations. The most glaring limitation is the low reliability of the conflict tactics scales involving reasoning. The conflict tactic scales were adapted, with the permission of the scale's creators, to fit the current research, as had been done by other professionals in their research. The scales are a part of a larger measure, which assesses violence tactics as well as verbal aggression and reasoning. The 
original scale, in fact, is primarily used in spousal and family violence studies. The subdivision of the scale and the fact that the researcher in this study added more items to the reasoning scale may have compromised the reliability of the measure. Though when the items that the researcher added were removed, and reliability assessed, the reliabilities decreased. Regardless, the low reliability of the measure, affects all of the results concerning reasoning tactics. Future studies involving conflict tactics in romantic relationships should asses reasoning through a more reliable measure that has been tested in a number of studies.

Finally, the sample population limits this research. Participants for this study were obtained from a large lecture introductory communication course. Participants were students, and were given extra credit for their participation in the study. There is inherent homogeneity in college student populations. Education levels and cultural backgrounds are not as diverse in the college student population as they are in the real world. Future research should examine the aforementioned relationships along more and differing demographic lines. Also this study did not control for the sexual orientation of the participants. Future research might examine these concepts along the lines of sexual orientation, in conjunction with relationship turning points and transgressions, and along marital typologies such as those proposed by Fitzpatrick (Fitzpatrick, 1988). Duration of the relationship was examined in a post hoc analysis, and was not found to correlate significantly with any of the variables under study. Future research might take this into account when studies are proposed.

Exploration of the current data set revealed a number of findings that were not anticipated. Future research might make the argument for more direct relationships 
between verbal aggression and emotion-based personality traits. Though the weakness of the reasoning tactics findings can be contributed to low validity, and the use of subscales out of context, the findings on verbal aggression are significant despite these limitations. The use of more reliable verbal aggression measures may amplify the nature of the current results. Future research should also entail the exploration of other relationship constructs like relational maintenance, turning points, and conflict resulting in relationship termination.

Emotions are important aspects of romantic relationships. The degree to which people use their emotions in making tactical decisions in conflict has an affect on relationship satisfaction. Emotional intelligence is highly correlated with affective orientation but has been shown to relate to variables differently than affective orientation. This suggests that emotional intelligence and affective orientation are distinct concepts, and that they play different roles in romantic relationships. The findings of this research have suggested that the study of emotion-based personality traits, and behavioral frequencies, such as conflict tactics, as they relate to relationship satisfaction is significant and in the proposed directions, but far from conclusive. Future research is needed to clarify strengthen and amend the ideas and findings of this research. 


\section{REFERENCES}

Anderson, P. A., \& Guerrero, L. K. (1998). The handbook of communication and emotion. San Diego, CA: Academic Press.

Argyle, M., \& Furnham, A. (1983). Sources of satisfaction and conflict in long-term relationships. Journal of Marriage and the Family, 45, 481-493.

Bell, D.C., Chafetz, J.S., \& Horn, L.H. (1982). Marital conflict resolution: A study of strategies and outcomes. Journal of Family Issues, 3, 111-131.

Billingham, R.E. (1987). Courtship violence: The pattern of conflict resolution strategies across seven levels of emotional commitment. Family Relations, 36, 283-289.

Booth-Butterfield, M., \& Andrighetti, A. (April, 1993). The role of affective orientation and nonverbal sensitivity in the interpretation of communication in acquaintance rape. Paper presented at the annual convention of the Eastern Communication Association, New Haven, CT.

Booth-Butterfield, M., \& Booth-Butterfield, S. (1990). Conceptualizing affect as information in communication production. Human Communication Research, 16, $451-476$.

Booth-Butterfield, M., \& Booth-Butterfield, S. (1994). The affective orientation to communication: Conceptual and empirical distinctions. Communication Quarterly, 42, 331-344.

Booth-Butterfield, M., \& Booth-Butterfield, S. (1996). Using your emotions: Improving the measurement of affective orientation. Communication Research Reports, 13, 157-163.

Booth-Butterfield, M., \& Booth-Butterfield, S. (1998). Emotionality and affective 
orientation. In J. C. McCroskey, J. A. Daly, M. M. Martin, \& M. J. Beatty (Eds.), Communication and personality: Trait perspectives (pp. 171-189). Cresskill, N.J.: Hampton Press.

Booth-Butterfield, M., Hinkle, S. D., \& Booth-Butterfield, S. (1998). Satisfaction and affective orientation in interpersonal relationships.

Braiker, H. B., \& Kelley, H. H. (1979). Conflict in the development of close relationships. In R. Burgess \& T. Huston (Eds.) Social change in developing relationships (pp.135-169). New York: Academic.

Burleson, B. R., \& Samter, W. (1994). A social skills approach to relationship maintenance: How individual differences in communication skills affect the achievement of relationship functions. In D. J. Canary, \& L. Stafford (Eds.). Communication and relational maintenance. San Diego, CA: Academic.

Burleson, B.R., \& Planalp, S. (2000). Producing emotion(al) messages. Communication Theory, 2, 221-250.

Buysse, A., De Clercq, A., Verhofstadt, L., Heene, E., Roeyers, H., \& Van Oost, P. (2000). Dealing with relational conflict: A picture in milliseconds. Journal of Social and Personal Relationships, 17, 574-597.

Canary, D. J., \& Hause, K. S. (1993). Is there any reason to research sex differences in communication? Communication Quarterly, 41, 129-144.

Canary, D. H., \& Spitzberg, B. H. (1989). A model of perceived competence of conflict strategies. Human Communication Research, 15, 630-649.

Canary, D.H., \& Spitzberg, B.H. (1990). Attribution biases and associations between conflict strategies and competence outcomes. Communication Monographs, 57, 
139-151.

Coser, L. A. (1956). The function of social conflict. Glancoe, IL: Free Press.

Cramer, D. (2000). Relationship satisfaction and conflict style in romantic relationships. Journal of Psychology, 134, 337-342.

Cupach, W.R. (2000). Advancing understanding about relational conflict. Journal of Personal and Social Relationships, 17, 697-703.

Cupach, W. R., \& Canary, D. J. (1995). Managing conflict and anger: Investigating the sex stereotype hypothesis. In P. J. Kalbfleisch \& M. J. Cody (Eds.) Gender, power, and communication in human relationships (pp 233-252). Hillsdale, NJ: Lawrence Erlbaum Associates.

Davis, H. M., \& Oathout, H. A. (1987). Maintenance of satisfaction in romantic relationships: Empathy and relational competence. Journal of Personality and Social Psychology, 53, 397-410.

Deaux, K., \& Lewis, L. L. (1984). The structure of gender stereotypes: Interrelationships among components and gender label. Journal of Personality and Social Psychology, 46, 991-1004.

Detusch, M. (1973). The resolution of conflict: Constructive and destructive processes. New Haven, CT: Yale University Press.

Dillard, J.P., Kinney, T.A., \& Cruz, M.G. (1996). Influence, appraisals and emotions in close relationships. Communication Monographs, 63, 105-130.

Dolin, D. \& Booth-Butterfield, M. (1993). Reach out and touch someone: Analysis of nonverbal comforting responses. Communication Quarterly, 41, 383-393.

Duck, S. (1994). Steady as (s)he goes: Relational maintenance as a shared meaning 
system. In D. J. Canary \& L. Stafford (Eds.), Communicaiton and relational maintenance. San Diego, CA: Academic.

Erbert, L. A., \& Duck, S. W. (1997). Rethinking satisfaction in personal relationships from a dialectical perspective. In R. S. Sternberg \& M. Hojjat (Eds.). Satisfaction in close relationships (pp.190-216). New York: Guilford.

Fitzpatrick, M.A. (1988). Between husbands and wives. Newbury Park, CA: Sage

Ford, M.E., \& Tisak, M.S. (1983). A further search for social intelligence. Journal of Educational Psychology, 75, 196-206.

Frymier, A. B., Klopf, D. W., \& Ishii, S. (1990). Affect orientation: Japanese compared to Americans. Communication Research Reports, 7, 63-66.

Gardner, H. (1983). Frames of mind: The theory of multiple intelligences. New York: Basic Books.

Goleman, D. (1995). Emotional intelligence: Why it can matter more than IQ. New York: Bantam Books.

Gottman, J. M. (1979). Marital interaction: Experimental investigations. NewYork: Academic Press.

Johnston, D. D., Stinski, M., \& Meyers, D. (1993). Development of an alexithymia instrument to measure the diminished communication of affect. Communication Research Reports, 10, 149-160.

Keicolt-Glaser, J. K., \& Newton, T. L. (2001). Marriage and health: His and hers. Psychological Bulletin, 127, 472-503.

Kemper, C. L. (1999). EQ vs. IQ. Communication World, 16, 15-19.

Knapp, M. L. (2000). Communicating emotion: Social, moral, and cultural processes. 
The Quarterly Journal of Speech, 86, 488-489.

Mayer, J. D., Caruso, D. R., \& Salovey, P. (2000). Selecting a measure of emotional intelligence: The case for ability testing. In R.Baron \& J.D. A. Parker (Eds.), Handbook of Emotional Intelligence (pp. 320-342). New York: Jossey-Bass.

McCroskey, J. C., \& Beatty, M. J. (1998). Communication apprehension. In J. C. McCroskey, J. A. Daly, M. M. Martin, M. J. Beatty (Eds.) Communication and personality: Trait perspectives (pp. 215-231). Cresskill, NJ: Hampton Press.

Meeks, B. S., Hendrick, S. S. \& Hendrick C. (1998). Communication, love and relationship satisfaction. Journal of Social and Personal Relationships, 15, 755774.

Metz, M. E. \& Rosser, B. R. S. (1994). Differences in conflict resolution styles among heterosexual, gay and lesbian couples. Journal of Sex Research, 31, 293-309.

Murray, S. L., Holmes, J. G., \& Griffin D. W. (1996). The benefits of positive illusions: Idealization and the construction of satisfaction in close relationships. Journal of Personality and Social Psychology, 70, 79-98.

Peterson, D. R. (1983). Conflict. In H. H. Kelley, E. Berscheid, A. Christenson, J. H. Harvey, T. L. Huston, G. Livingee, E. McClintock, L. A. Peplan, \& D. R. Peterson (Eds.). Close relationships (pp.360-396). New York: Freeman.

Petrides, K. V., \& Furnham, A. (2000). Gender differences in measured and selfestimated trait emotional intelligence. Sex Roles, 42, 449-461.

Pfeiffer, S.I. (2001). Emotional intelligence: A popular but elusive construct. Reoper Review, 23, 138-142.

Planalp, S. (1993). Communication, cognition, and emotion. Communication 
Monographs, 60, 3-9.

Planalp, S. (1999). Communicating emotion: Not just for interpersonal scholars anymore. Communication Theory, 9, 216-228.

Polednik, L. (2000). Personality and emotional intelligence. The British Journal of Administrative Management, 19, 9-11.

Roloff, M. E., \& Cloven, D. H. (1994). Maintaining violated relationships. In D. J. Canary \& L. Stafford (Eds.) Communication and relational maintenance (pp.2243). San Diego: Academic Press.

Rusbult, C. E. (1983). A longitudinal test of the investment model: The development (and deterioration) of satisfaction and commitment in heterosexual involvements. Journal of Personality and Social Psychology, 45, 101-117.

Rusbult, C. E., Drigotas, S. M., \& Verette, J. (1994). The investment model: An interdependence analysis of commitment processes and relationship maintenance phenomena. In D. J. Canary, \& L. Stafford (Eds.). Communication and relational maintenance. San Diego, CA: Academic.

Salovey, P., \& Mayer, J.D. (1990). Emotional intelligence. Imagination, Cognition and Personality, 9, 185-211.

Salovey, P., Mayer, J. D., Caruso, D., \& Lopes, P. N. (2001). Measuring emotional intelligence as a set of abilities with the MSCEIT. In S. J. Lopez \& C. R. Snyder (Eds.). Handbook of positive psychology assessment. Washington, DC: APA Unpublished copy of a perspective book chapter.

Schutte, N. S., Malouff, J. M., Bobik, C., \& Coston, T. D. (2001). Emotional intelligence and interpersonal relations. The Journal of Social Psychology, 141, 
523-536.

Schutte, N. S., Malouff, J. M., Hall, L. E., Haggerty, D. J., Cooper, J. T., Golden, C. J., \& Dornheim, L. (1998). Development and validation of a measure of emotional intelligence. Personality and Individual Differences, 25, 167-177.

Shea, B. C., \& Pearson, J. C. (1986). The effects of relationship type, partner intent, and gender on the selection of relationship maintenance strategies. Communication Monographs, 53, 352-364.

Sillars, A. L., \& Weisberg, J. (1987). Conflict as a social skill. In M.E. Roloff, \& G.R. Miller (Eds.) Interpersonal processes: New directions in communication research (pp.140-169). Newbury Park: Sage.

Spanier, G. B. (1976). Measuring dyadic adjustment: New scales for assessing the quality of marriage and similar dyads. Journal of Marriage and the Family, $38,15-28$.

Sprecher, S., \& Metts, S. (1995). Domains of expressive interaction in intimate relationships: Associations with satisfaction and commitment. Family Relations, 44, 203-211.

Sprether, S. (2001). Equity and social exchange in dating couples: Associations with satisfaction, commitment, and stability. Journal of Marriage and the Family, 63, 599-614.

Sternberg, R. J., \& Soriano, L. J. (1984). Styles of conflict resolution. Journal of Personality and Social Psychology, 47, 115-126.

Stets, J. E., \& Straus, M. A. (1990a). Gender differences in reporting marital violence and its medical and psychological consequences. In M.A. Straus \& R.J. Gelles 
(Eds.) Physical violence in American families (pp. 151-167). New Brunswick:

Transaction

Stets, J. E., \& Straus, M. A. (1990b). The marriage license as a hitting license: A comparison of assaults in dating, cohabitating and married couples. In M. A. Straus \& R. J. Gelles (Eds.), Physical violence in American families (pp. 227244). New Brunswick; Transaction.

Straus, M.A. (1990). Measuring intrafamily conflict and violence: The conflict tactics scale. In M. A. Straus \& R. J. Gelles (Eds.), Physical violence in American families (pp. 29-73). New Brunswick: Transaction.

Straus, M. A., \& Gelles, R. J. (1990). Physical violence in American families. New Brunswick, NJ: Transaction

Wanzer, M., Booth-Butterfield, M., \& Booth-Butterfield, S. (1995). The funny people: A source-orientation to the communication of humor. Communication Quarterly, $43,142-154$.

Watson, D, Hubbard B., \& Wiese, D. (2000). General traits of personality and affectivity as predictors of satisfaction in intimate relationships: Evidence from self- and partner-ratings. Journal of Personality ,68, 413-449.

Yelsma, P. (1995). Couples' affective orientations and their verbal abusiveness. Communication Quarterly, 43, 100-114

Zammutto, M.L., London, M., Rowland, K.W. (1979). Effects of sex on commitment and conflict resolution. Journal of Applied Psychology, 64, 227-231. 
TABLE 1

Descriptive Statistics of Variables Under Study

\begin{tabular}{ccccc}
\hline Variable: & Range & $\underline{\mathbf{M}}$ & $\underline{\text { SD }}$ & $\underline{\alpha}$ \\
\hline SCTVA & $7-26$ & 14.31 & 3.45 & .65 \\
SCTR & $20-38$ & 30.58 & 3.10 & .42 \\
PCTVA & $8-25$ & 14.45 & 3.93 & .68 \\
PCTR & $16-37$ & 27.58 & 4.38 & .62 \\
AO & $41-96$ & 74.79 & 9.74 & .89 \\
EI & $93-151$ & 120.00 & 11.67 & .86 \\
CON & $22-77$ & 56.76 & 8.72 & .85 \\
SAT & $14-61$ & 46.74 & 8.43 & .89 \\
COH & $8-30$ & 22.48 & 3.87 & .74 \\
AFF & $3-14$ & 11.13 & 1.95 & .43 \\
DAS & $70-180$ & 137.10 & 19.39 & .92 \\
\hline \hline
\end{tabular}

Note. The variables in this table are represented with abbreviations as follows:

$\overline{\text { SCTVA }}=$ Participants use of verbally aggressive conflict tactics.

$\mathbf{S C T R}=$ Participants use of reasoning conflict tactics.

PCTVA = Participants perceptions of their romantic partner's use of verbally aggressive conflict tactics.

PCTR $=$ Participants perceptions of their romantic partner's use of reasoning conflict tactics.

$\mathbf{A O}=$ Affective orientation.

$\mathbf{E I}=$ Emotional intelligence.

$\mathbf{C O N}=$ Dyadic consensus.

SAT $=$ Relationship satisfaction.

$\mathbf{C O H}=$ Dyadic cohesion .

$\mathbf{A F F}=$ Affective displays in romantic relationships.

$\mathbf{D A S}=$ Dyadic adjustment (measured as a combination of four subscales). 
TABLE 2

Pearson Correlations Between Variables

\begin{tabular}{|c|c|c|c|c|c|c|c|c|c|c|c|}
\hline & SCTVA & SCTR & PCTVA & PCTR & AO & EI & CON & SAT & $\mathrm{COH}$ & AFF & DAS \\
\hline SCTVA & & $-.34^{* * *}$ & $.58^{\star \star \star \star}$ & $-.30^{\star * \star *}$ & $-.18^{*}$ & $-.22^{* *}$ & $-.24^{* *}$ & $-.41^{* * \star *}$ & $-.24^{* *}$ & $-.18^{*}$ & $-.36^{\star \star \star \star}$ \\
\hline SCTR & & & $-.29^{\star \star *}$ & $.30^{* * *}$ & 13 & $.26^{\star \star \star}$ & .10 & $.19^{*}$ & $.19^{*}$ & $.18^{*}$ & $.18^{*}$ \\
\hline PCTVA & & & & $-.40^{\star * \star *}$ & $-.18^{*}$ & $-.17^{*}$ & $-.37^{\star \star * *}$ & $-.54^{\star * * *}$ & $-.40^{* * * *}$ & $-.33^{* * * *}$ & $-.50^{\star \star \star \star}$ \\
\hline PCTR & & & & & $.23^{\star *}$ & $.22^{* \star}$ & $.37^{\star \star \star \star}$ & $.41^{* \star \star *}$ & $.34^{\star \star * *}$ & $.31^{* \star \star *}$ & $.44^{\star * \star *}$ \\
\hline AO & & & & & & $.58^{* * * *}$ & $.33^{* \star \star *}$ & $.41^{* \star \star *}$ & $.34^{* * * *}$ & $.21^{\star * *}$ & $.41^{* * \star *}$ \\
\hline EI & & & & & & & $.21^{* * *}$ & $.26^{\star \star \star}$ & $.27^{\star \star \star}$ & $.17^{*}$ & $.28^{* * *}$ \\
\hline CON & & & & & & & & $.60^{\star * \star *}$ & $.53^{\star \star \star *}$ & $.51^{\star \star \star \star}$ & $.87^{\star \star \star \star}$ \\
\hline SAT & & & & & & & & & $.66^{\star * \star *}$ & $.57^{* \star * *}$ & $.90^{* * * *}$ \\
\hline $\mathrm{COH}$ & & & & & & & & & & $.42^{\star \star * \star}$ & $.77^{\star \star \star *}$ \\
\hline AFF & & & & & & & & & & & $.67^{* * * *}$ \\
\hline DAS & & & & & & & & & & & \\
\hline
\end{tabular}

Note: Probability levels are indicated by the following notations, ${ }^{*} \mathrm{p}<.05,{ }^{* *} \mathrm{p}<.01$, $* * * \mathrm{p}<.0001$, and $* * * * \mathrm{p}<.0001$.

Note: The variables in this table are represented with abbreviations as follows:

SCTVA $=$ Participants use of verbally aggressive conflict tactics.

$\mathbf{S C T R}=$ Participants use of reasoning conflict tactics.

PCTVA= Participants perceptions of their romantic partner's use of verbally aggressive conflict tactics.

$\mathbf{P C T R}=$ Participants perceptions of their romantic partner's use of reasoning conflict tactics.

$\mathbf{A O}=$ Affective orientation

$\mathbf{E I}=$ Emotional intelligence.

CON= Dyadic consensus.

SAT $=$ Relationship satisfaction.

$\mathbf{C O H}=$ Dyadic cohesion .

$\mathbf{A F F}=$ Affective displays in romantic relationships.

DAS $=$ Dyadic adjustment (measured as a combination of four subscales). 


\section{APPENDIX A}

\section{Emotional Intelligence Scale.}

Reproduced with the permission of the authors Schutte and Malouff (1998).

Directions: Each of the following items asks you about your emotions or reactions associated with emotions. After deciding whether a statement is generally true for you, using the 5-point scale ( 1 as strongly disagree to 5 as strongly agree) to respond to the statement. There are no right or wrong answers. So please give the response that best describes you.

$\begin{array}{ccccc}1 & 2 & 3 & 4 & 5 \\ \text { Strongly disagree } & \text { Disagree } & \text { Neutral } & \text { Agree } & \text { Strongly Agree }\end{array}$

1. I know when to speak about my personal problems to others.

2. When I am faced with obstacles, I remember times I faced similar obstacles and overcame them.

3. I expect that I will do well on most things I try.

4. Other people find it easy to confide in me.

5. I find it hard to understand the non-verbal messages of other people.

6. Some of the major events in my life have led me to re-evaluate what is important and not important.

7. When my mood changes, I see new possibilities.

8. Emotions are one of the things that make my life worth living.

9. I am aware of my emotions as I experience them.

10. I expect good things to happen.

11. I like to share my emotions with others.

12. When I experience a positive emotion, I know how to make it last.

13. I arrange events others enjoy.

14. I seek out activities that make me happy.

15. I am aware of the non-verbal messages that I send out to others.

16. I represent my self in a way that makes a good impression on others.

17. When I am in a positive mood, solving problems are easy for me.

18. By looking at their facial expressions, I recognize the emotions people are experiencing.

19. I know why my emotions change.

20. When I am in a positive mood, I am able to come up with new ideas.

21. I have control over my emotions.

22. I easily experience my emotions as I recognize them.

23. I motivate myself by imagining a good outcome to the tasks I take on.

24. I compliment others when they have done something well.

25. I am aware of the non-verbal messages that other people send.

26. When another person tells me about an important event in his or her life, I almost feel as though I have experienced this event myself.

27. When I feel a change in emotions, I tend to come up with new ideas.

28. When I am faced with a challenge, I give up because I believe I will fail.

29. I know what other people are feeling just by looking at them.

30. I help other people feel better when they are down.

31. I use good moods to help myself keep trying in the face of obstacles.

32. I can tell how people are feeling by listening to the tone of their voice.

33. It is difficult for me to understand why people feel the way they do. 


\section{APPENDIX B}

Original Version of the Affective Orientation Scale

(Booth-Butterfield \& Booth-Butterfield, 1990)

The following statements refer to the feelings and emotions people have and how people use their feelings and emotions to guide their behavior. There are no right or wrong answers. Also realize that emotions and feelings can be positive or negative. A person can feel anger; another can feel love and tenderness. Both cases, however, are emotion. These statements refer to both types, positive and negative. Please respond to the following statements using this scale:

\section{5}

Strongly Agree
$4 \quad 3$

Agree

Uncertain

2

1

Disagree Strongly Disagree

1. I am aware of my feelings.

2. I use my feelings to determine what I should do in situations.

3. My feelings and emotions are very important to me.

4. I listen to what my "gut" or "heart" says in many situations.

5. My emotions tell me what to do in many situations.

6. I try not to let feelings guide my actions.

7. I trust my feelings to guide my behavior.

8. I don't pay much attention to my emotions most of the time.

9. My feelings tell me a lot about how to act in a given situation.

10. The intensity of my emotion does not change much from situation to situation.

11. I use my feelings to determine whether to trust another person.

12. I learn a lot about myself on the basis of my feelings.

13. I am not usually aware of my feelings at any given moment.

14. Feelings are a valuable source of information.

15. My feelings don't seem to be very intense or strong.

16. I use my feelings to guide me more than other people do.

17. Feelings only interfere with behavior.

18. I orient to people through my emotions.

19. My emotions have many different levels of intensity; I can be angry for example, or very angry.

20. I seem to have just a few basic emotions. 


\section{APPENDIX C}

The Conflict Tactics Scale for Romantic Relationships (participant)

No matter how well a couple gets along, there are times when they disagree, get annoyed with each other, or just have spats or fights because they are in a bad mood, or tired or for some other reason. They also use different ways of trying to settle their differences. The following statements are things that you and your partner might do when you have an argument. Please respond to each item by indicating how many times you did the following in your relationship. Use the scale below for your answers:

$\begin{array}{ccccc}0 & 1 & 2 & 3 & 4 \\ \text { never } & \text { seldom } & \text { sometimes } & \text { often } & \text { always }\end{array}$

1. Discussed an issue calmly.

2. Got information to back up my side of the issue.

3. Brought in or tried to bring in someone else to settle the issue.

4. Insulted or swore at the other person.

5. Sulked or refused to talk about an issue.

6. Stomped out of the room, house, or yard.

7. Cried.

8. Did or said something to spite the other person.

9. Threatened to hit or throw something at them.

10. Threw, smashed, hit or kicked something.

11. *Took a break from the discussion to cool off.

12. *Tried to see things from the other person's point of view.

13. *Considered sacrificing your needs for theirs.

14. *Made a compromise.

15. Yelled at the other person.

\section{APPENDIX D}

The Conflict Tactics Scale for Romantic Relationships: (participants significant other)

No matter how well a couple gets along, there are times when they disagree, get annoyed with each other, or just have spats or fights because they are in a bad mood, or tired or for some other reason. They also use different ways of trying to settle their differences. The following statements are things that you and your partner might do when you have an argument. Please respond to each item by indicating how many times your partner did the following in your relationship. Use the scale below for your answers:
0
1
never
seldom
2
3
sometimes
often
4
always

1. Discussed an issue calmly.

2. Got information to back up my side of the issue.

3. Brought in or tried to bring in someone else to settle the issue.

4. Insulted or swore at you.

5. Sulked or refused to talk about an issue.

6. Stomped out of the room, house, or yard.

7. Cried.

8. Did or said something to spite you.

9. Threatened to hit or throw something at you.

10. Threw, smashed, hit or kicked something.

11. *Took a break from the discussion to cool off.

12. *Tried to see things from your point of view.

13. *Considered sacrificing their needs for yours.

14. *Made a compromise.

15. Yelled at you. 


\section{$\underline{\text { APPENDIX E }}$}

Dyadic Adjustment Scale (Spanier, 1976)

Most persons have disagreements in their relationships. Please indicate the approximate extent of agreement or disagreement between you and your partner for each item in the following list. Please respond using the following scale:

\begin{tabular}{llllll}
$\mathbf{5}$ & $\mathbf{4}$ & $\mathbf{3}$ & $\mathbf{2}$ & \multicolumn{1}{c}{$\mathbf{1}$} & \multicolumn{1}{c}{$\mathbf{0}$} \\
Always & Almost & Occasionally & Frequently & Almost & Always \\
Agree & Always & Disagree & Disagree & Always & Disagree \\
& Agree & & & Disagree &
\end{tabular}

1. Handling finances.

2. Matters of recreation.

3. Religious matters.

4. Demonstrations of affection.

5. Friends.

6. Sexual relations.

7. Conventionality (correct or proper behavior).

8. Philosophy of life.

9. Ways of dealing with parents or other family members.

10. Aims, goals and things believed important.

11. Amount of time spent together.

12. Making major decisions.

13. Household tasks.

14. Leisure time interests and activities.

15. Career decisions.

Respond to the following items using this scale:

$\begin{array}{cccccc}\mathbf{0} & \mathbf{1} & \mathbf{2} & \mathbf{3} & \mathbf{4} & \mathbf{5} \\ \text { All } & \text { Most of } & \text { More often } & \text { Occasionally } & \text { Rarely } & \text { Never } \\ \text { the time } & \text { the time } & \text { than not. } & & & \end{array}$

16. How often do you discuss or have you considered separation or termination of your relationship?

17. How often do you or your significant other leave the house after a fight.

18. In general, how often do you think that things between you and your partner are going well. 
19. Do you confide in your significant other?

20. Do you ever regret that you got together with your significant other?

21. How often do you and your significant other quarrel?

22. How often do you and your significant other get on each other's nerves?

23. Do you kiss your significant other?

24. How often do you and your mate engage in outside interests together?

How often do the following events occur between you and your significant other? Respond using the following scale.

o 1

Never
Less than once a month
2

Once or twice a month
3

Once or twice a week
4

Once a

day
5

More

often

24. Have a stimulating exchange of ideas.

25. Laugh together.

26. Calmly discuss something.

27. Work together on a project.

28. The following line represents different degrees of happiness in your relationship. The middle point, "happy," represents the degree of happiness of most relationships. Please circle the dot which best describes the degree of happiness, all things considered in your relationship.

\begin{tabular}{ccccccc}
\multicolumn{1}{c}{1} & 2 & 3 & 4 & 5 & 6 \\
\hline $\begin{array}{l}\text { Extremely } \\
\text { Unhappy }\end{array}$ & $\begin{array}{c}\text { Fairly } \\
\text { Unhappy }\end{array}$ & $\begin{array}{c}\text { A Little } \\
\text { Unhappy }\end{array}$ & Happy & $\begin{array}{c}\text { Very } \\
\text { Happy }\end{array}$ & $\begin{array}{c}\text { Extremely } \\
\text { Happy }\end{array}$ & Perfect
\end{tabular}

29. Please choose one of the following statements that BEST describes how you feel about the future of your relationship. Place an $\mathrm{X}$ by your choice.

I want desperately for my relationship to succeed, and would go to almost any length to see that it does.

I want very much for my relationship to succeed, and I will do all I can to see that it does.

I want very much for my relationship to succeed, and will do my fair share to see that it does.

It would be nice if my relationship succeeded, but I can't do much more than I am doing now to help it succeed.

It would be nice if my relationship succeeded, but I refuse to do more than I am doing now to keep the relationship going.

My relationship can never succeed, and there is no more that I can do to keep the relationship going.

30. Couples often disagree or have differences of opinion. In the past few weeks has your partner not showing you love caused a problem. (Please circle one) 


\section{APPENDIX F}

Demographic Information:

1. Number of Months in the Relationship:

2. Sex

3. Major

4. Year in College:

Freshman

Sophomore

Junior

Senior

Other

5. Relationship status:
Married
Dating
Single
Divorced
Cohabiting 


\section{APPENDIX G}

\section{Cover Letter and Definition of Terms}

\section{Dear Student Participant,}

The purpose of this study is to understand the nature of emotion and conflict in romantic relationships. There are no special qualifications needed to participate in this study. Participation involves completing the questionnaire, giving the same questionnaire your significant other to fill out, and returning the questionnaires to the researcher. You may withdraw from the study at any point without penalization. This research will be used in the completing of a master's thesis.

Thank you in advance for your participation. Your responses will be kept anonymous. All responses will be kept confidential. Please do not write your name, or any identifying marks on the questionnaire.

Individuals are free to participate or decline. Class, academic, and athletic standing will not be affected if you choose not to participate in the study. All participation is voluntary and the information gathered will be used for the completion of a research project. If you have any questions or concerns, I can be reached at (304) 293-3905. My advisor, Dr. Melanie Booth-Butterfield can be reached at the same number if you have any further questions.

Sincerely,

Christine A. Rudnicki

A romantic relationship is one in which partners consider their significant others as girlfriends, boyfriends, husbands, or wives. You would introduce the other person with these titles. No matter how well a couple gets along, there are times when they disagree, get annoyed with each other, or just have spats or fights because they are in a bad mood, or tired or for some other reason. They also use different ways of trying to settle their differences. The following statements are things that you and your partner might do when you have an argument. Please respond to each item by indicating how many times you did the following in your relationship. Use the scale below for your answers: 